NBER WORKING PAPER SERIES

\title{
THE OUTPUT AND WELFARE EFFECTS OF GOVERNMENT SPENDING SHOCKS OVER THE BUSINESS CYCLE
}

\author{
Eric Sims \\ Jonathan Wolff \\ Working Paper 19749 \\ http://www.nber.org/papers/w19749
NATIONAL BUREAU OF ECONOMIC RESEARCH
1050 Massachusetts Avenue
Cambridge, MA 02138 \\ December 2013
}

This paper previously circulated as "The Output and Welfare Effects of Fiscal Shocks over the Business Cycle." We are grateful to Rudi Bachmann, Bob Flood, Tim Fuerst, Robert Lester, Michael Pries, Jeff Thurk, and seminar participants at Notre Dame, the University of Texas at Austin, the University of Mannheim, Purdue University, Miami University, Eastern Michigan University, Dickinson College, Montclair State University, and the Fall 2013 Midwest Macro Meetings for several comments which have substantially improved the paper. The views expressed herein are those of the authors and do not necessarily reflect the views of the National Bureau of Economic Research.

NBER working papers are circulated for discussion and comment purposes. They have not been peerreviewed or been subject to the review by the NBER Board of Directors that accompanies official NBER publications.

(C) 2013 by Eric Sims and Jonathan Wolff. All rights reserved. Short sections of text, not to exceed two paragraphs, may be quoted without explicit permission provided that full credit, including $\odot$ notice, is given to the source. 
The Output and Welfare Effects of Government Spending Shocks over the Business Cycle Eric Sims and Jonathan Wolff

NBER Working Paper No. 19749

December 2013, Revised July 2015

JEL No. E0,E1,E2,E3,E31,E6,E62

\begin{abstract}
$\underline{\text { ABSTRACT }}$
This paper studies the state-dependence of the output and welfare effects of shocks to government purchases in a canonical medium scale DSGE model. When monetary policy is characterized by a Taylor rule, the output multiplier (the change in output for a one unit change in government spending) is countercyclical but close to constant across states of the business cycle, whereas the welfare multiplier (the consumption equivalent change in a measure of aggregate welfare for the same change in government spending) is quite volatile and procyclical. These results are robust to different means of fiscal finance. When the nominal interest rate is unresponsive to economic conditions, such as would be the case at the zero lower bound, both the output and welfare multipliers are larger and move significantly more across states than under a Taylor rule. The welfare multiplier is still procyclical under passive monetary policy, albeit less so than under a Taylor rule.
\end{abstract}

Eric Sims

Department of Economics

University of Notre Dame

723 Flanner Hall

South Bend, IN 46556

and NBER

esims1@nd.edu

Jonathan Wolff

University of Notre Dame

434 Flanner Hall

Notre Dame, IN 46556

jwolff2@nd.edu 


\section{Introduction}

The recent Great Recession has led to renewed interest in fiscal stimulus as a tool to fight recessions. There nevertheless seems to be a lack of consensus concerning some fundamental questions. How large is the government spending multiplier? Does it vary in magnitude over the business cycle? What are the welfare implications of government spending shocks? Is countercyclical government spending desirable? This paper seeks to provide some answers to these questions.

We study the effects of government spending shocks in an estimated medium scale New Keynesian dynamic stochastic general equilibrium (DSGE) model along the lines of Christiano, Eichenbaum, and Evans (2005) and Smets and Wouters (2007). The model features price and wage stickiness, capital accumulation, several sources of real inertia, and a number of shocks. It also includes government spending shocks and a rich fiscal financing structure. The potential benefits of government spending are modeled by assuming that government spending enters the utility function of households. Our paper departs from most of the existing literature along two key dimensions. First, we solve the model via higher order perturbation as opposed to linearization, which allows us to investigate whether there are important state-dependent effects of changes in government spending. Second, rather than focusing solely on how government spending shocks affect output, we also study how changes in government spending impact a measure of aggregate welfare. In doing so, we adopt the following terminology. We define the "output multiplier" as the change in output for a one unit change in government spending, which is the standard definition of the fiscal multiplier. The "welfare multiplier" is defined as the change in aggregate welfare for a one unit change in government spending, which we express in consumption equivalent units.

When monetary policy is characterized by a Taylor rule and government spending is financed via lump sum taxes, the output multiplier is about 0.9 and is close to constant across states. While we do find that the multiplier is countercyclical in the sense that it co-varies negatively with the level of output, its movements across states are quantitatively small. The welfare multiplier, in contrast, is quite volatile across states. ${ }^{1}$ It tends to be low during recessions and high in expansions, and its correlation with the level of output is about 0.4. The procyclicality of the welfare multiplier suggests that countercyclical government spending is undesirable in the model. When government spending is financed via changes in distortionary tax rates, the output multiplier is smaller but varies more across states than when government finance comes via lump sum taxes. While it is robustly countercyclical, the maximum variation in the output multiplier across states is never more than about 0.1 when fiscal finance comes through changes in distortionary taxes.

\footnotetext{
${ }^{1}$ For reasons that will be made clearer in Section 2, it is difficult to identify the sign and magnitude of the welfare multiplier. We assume that government spending enters household utility in an additively separable way. This means that the parameters which map government spending into utility are irrelevant for equilibrium dynamics and therefore impossible to identify empirically. It is therefore not possible to determine whether the welfare multiplier is on average positive or negative or what its magnitude is. For this reason, our focus is on the state-dependence of the welfare multiplier, not its absolute magnitude. Our baseline approach is to set the parameter mapping government spending into utility in such a way as to normalize the welfare multiplier to zero evaluated in the non-stochastic steady of the model. This normalization does not affect any of our results concerning the state-dependence of the welfare multiplier.
} 
Distortionary tax finance tends to heighten the procyclicality of the welfare multiplier across states, making countercyclical government spending even less desirable than under lump sum taxes. The welfare multiplier is most strongly procyclical conditional on "supply shocks" and is less procyclical conditional on "demand shocks."

Much of the renewed interest in fiscal policy has been driven by the recent period of low interest rates and the recognition that government spending may be substantially more effective at stimulating output when monetary policy is in a passive regime (e.g. Krugman, 1998; Eggertson and Woodford, 2003; and Christiano, Eichenbaum, and Rebelo, 2011). We simulate the effects of a passive monetary policy regime by assuming that the nominal interest rate is pegged at a fixed value for a number of periods, after which time policy reverts to a Taylor rule. The output multiplier is larger on average when the interest rate is pegged and can be substantially greater than one. The welfare multiplier is also larger on average under an interest rate peg relative to the Taylor rule. Both the output and welfare multiplier are significantly more volatile across states under an interest rate peg. For example, when the interest rate is pegged for two years, we find that the output multiplier varies between 0.7 and 1.8. Unlike the case where monetary policy is governed by a Taylor rule, this suggests that a first order solution method may be inadequate for studying the output effects of changes in government spending in a passive monetary regime, a point which has been made elsewhere (e.g. Braun, Koerber, and Waki, 2012). Even though the welfare multiplier is on average higher when monetary policy is passive, it is still procyclical, although its correlation with output is less positive than when monetary policy is governed by a Taylor rule. Though a passive monetary policy regime may be more likely in periods of depressed output, and the welfare multiplier is on average significantly higher during such periods, the welfare benefits of government spending arise not from output being low per se but rather from the passivity of monetary policy.

A robust conclusion from our analysis is that the welfare multiplier is procyclical. This result casts doubt on the desirability of countercyclical government spending as a general policy proscription, though there may exist some circumstances in which it is welfare-improving to increase government spending when output is low. A second result is that the output multiplier does not vary much across states conditional on being in an active monetary policy regime. These conclusions are of course dependent upon the nature of the model. We have not attempted to write down a model where countercyclical government spending is desirable, or a model which delivers large state-dependent output effects of changes in government spending. Rather, we have simply taken a canonical workhorse model parameterized to provide a good fit to recent US data and have investigated the state-dependence of the output and welfare effects of government spending shocks within that model. A different model, or different assumptions about the details of the workhorse model, could deliver different results. For example, in our model we assume that government expenditure is unproductive and enters the utility function of households in an additively separable way. It would be interesting to see how our results might differ if government spending were productive or if government spending interacted with household utility in different ways, such as being complementary with private consumption.

Our paper is related to a growing literature on fiscal policy multipliers. There is a large em- 
pirical literature that seeks to estimate fiscal output multipliers using reduced form techniques. Using orthogonality restrictions in estimated vector auto-regressions (VARs), Blanchard and Perotti (2002) identify shocks by ordering government spending first in a recursive identification, and report estimates of spending multipliers between 0.9 and 1.2. Mountford and Uhlig (2009) use sign restrictions in a VAR and find a multiplier of about 0.6. Ramey (2011) uses narrative evidence to construct a time series of government spending "news," and reports multipliers in the range of 0.6-1.2. This range aligns well with a number of papers that make use of military spending as an instrument for government spending shocks in a univariate regression framework (see, e.g. Barro, 1981; Hall, 1986 and 2009; Ramey and Shaprio, 1998; Barro and Redlick, 2011; and Eichenbaum and Fisher, 2005). The bulk of this empirical literature suggests that spending multipliers are in the neighborhood of 1 , which aligns with the average output multiplier in our model under an active monetary policy regime.

There is also a limited but growing literature that seeks to estimate state-dependent multipliers using econometric techniques. A drawback of this approach is that there are limited time series observations, particularly during periods of economic slack. Auerbach and Gorodnichenko (2012) estimate a regime-switching VAR model and find that the output multiplier is highly countercylical and as high as 3 during recessions and as low as 0 during expansions. Bachmann and Sims (2012) and Mittnik and Semmler (2012) also analyze non-linear time series models and reach similar conclusions. Nakamura and Steinsson (2014) consider a regression model that allows the multiplier to vary with the level of unemployment, and find that the multiplier is substantially larger when unemployment is high. Shoag (2015) also finds that the multiplier is higher when the labor market is characterized by significant slack.

Ramey and Zubairy (2014) analyze a new historical US data set and estimate a state-dependent time series model. They find no evidence that the output multiplier varies with the amount of slack in the economy. This result is broadly consistent with our results for the output multiplier under a Taylor rule, which we find to be close to constant across states. One criticism they make of the existing empirical literature on state-dependent multipliers concerns the conversion of elasticities into multipliers. Most empirical work uses logs of variables, and estimates the elasticity of output with respect to government spending. This elasticity is then converted to a multiplier by postmultiplying by the inverse of the average government spending share of output. Ramey and Zubairy (2014) argue that this approach is likely to make the output multiplier artificially high in recessions because the government spending share of output is countercyclical. Our analysis suggests that this criticism is quantitatively important. In particular, if we were to convert elasticities into multipliers using a fixed government spending share, we would find that the output multiplier varies between 0.8 and 1.1 across states, whereas in fact it is close to constant when monetary policy is characterized by a Taylor rule.

Another strand of the literature looks at the magnitude of fiscal multipliers within the context of DSGE models. Baxter and King (1993) is an early contribution. Zubairy (2014) estimates a medium-scale DSGE model similar to the one presented in the current paper and finds the output multiplier to be about 1.1. Coenen, et al (2012) calculate fiscal multipliers in seven popular DSGE 
models, and conclude that the output multiplier can be far in excess of one. Cogan, Cwik, Taylor and Wieland (2010) and Drautzberg and Uhlig (2011) conclude, in contrast, that the multiplier is likely less than unity. Leeper, Traum, and Walker (2011) use Bayesian prior predictive analysis not to produce a point estimate for the output multiplier, but rather to provide plausible bounds on it in a fairly general DSGE model. As noted by Parker (2011), almost all of the work on fiscal multipliers in DSGE models is based on linear approximations, which necessarily cannot address the state-dependence of multipliers.

Another related literature studies the output multiplier and its interaction with the stance of monetary policy. In particular, there is a growing consensus that the output multiplier can be substantially larger than normal under a passive monetary policy regime, such as the recent zero lower bound period. Early contributions in this regard include Krugman (1998), Eggertson and Woodford (2003), and Christiano (2004). Woodford (2011) conducts analytical exercises in the context of a conventional New Keynesian model without capital to study the output multiplier, both inside and outside of a zero lower bound episode. Christiano, Eichenbaum, and Rebelo (2011) analyze the consequences of the zero lower bound for the government spending multiplier in a DSGE model and find the multiplier can exceed 2. Though they are mostly focused on the output multiplier, they do briefly examine welfare, and find that it is optimal to substantially increase government spending at the zero lower bound. Nakata (2013) reaches a similar conclusion that it is optimal to increase government spending when the zero lower bound binds. Our analysis echoes these findings in that we find that the welfare multiplier is on average larger under an interest rate peg than when monetary policy follows a Taylor rule. Our paper differs from this literature in emphasizing the heightened state-dependence of both the output and welfare multipliers under a passive monetary policy regime.

The remainder of the paper is organized as follows. Section 2 considers a stripped down version of the medium scale DSGE model we use for quantitative analysis to try and develop some intuition for how (if at all) the output and welfare multipliers might vary across states. We derive analytic expressions for the output and welfare multipliers and discuss different forces at work. A key insight is that the welfare multiplier ought to be procyclical if the equilibrium is efficient. The more distorted the equilibrium is, the more countercyclical that distortion is, the larger is the output multiplier, and the more countercyclical is the output multiplier, the more likely it is for the welfare multiplier to be countercyclical. Section 3 presents the full medium scale DSGE model and estimates a subset of its parameters to fit recent US data. Section 4 carries out our primary quantitative exercises, examining how the output and welfare multipliers vary across states in the estimated DSGE model. The final section concludes.

\section{Intuition in a Simple NK Model}

This section seeks to build some intuition for how the output and welfare effects of government spending shocks might vary over the state of the business cycle. We do so in a simple, textbook version of the sticky price New Keynesian (NK) model. This framework is a special case of the 
more developed model in the next section which features capital, wage rigidity, several sources of real rigidity, and a variety of shocks. While it is ultimately a quantitative question as to how the output and welfare effects of government spending shocks vary over states of the business cycle, the intuition from this section will serve to elucidate several different forces which are at work.

The subsections below briefly lay out the problems of the different actors, characterize optimal decision rules, and discuss equilibrium and aggregation. We then use the optimality conditions to derive analytic expressions for the output and welfare effects of changes in government spending.

\subsection{Household}

We assume that there exists a representative household who receives utility from consumption and government spending and disutility from labor via the function $U\left(C_{t}, N_{t}, G_{t}\right)$. The household takes the time path of government spending as given. The utility function has the following properties: $U_{C}>0, U_{C C}<0, U_{N}<0, U_{N N} \leq 0, U_{G}>0$, and $U_{G G} \leq 0$. For simplicity, assume that flow utility is additively separable in these arguments, so that the cross-partial derivatives are all zero. The household maximizes the present discounted value of flow utility subject to a standard flow budget constraint. It can save in one period riskless bonds which pay nominal interest rate, $i_{t}$ :

$$
\begin{gathered}
\max _{C_{t}, N_{t}, B_{t}} E_{0} \sum_{t=0}^{\infty} \beta^{t} U\left(C_{t}, N_{t}, G_{t}\right) \\
\text { s.t. } \\
C_{t}+\frac{B_{t}-B_{t-1}}{P_{t}} \leq w_{t} N_{t}+\Pi_{t}-T_{t}+i_{t-1} \frac{B_{t-1}}{P_{t}}
\end{gathered}
$$

Here $B_{t-1}$ is the stock of bonds with which the household enters a period, $w_{t}$ is the real wage, $P_{t}$ is the price level, $\Pi_{t}$ is lump sum profit distributed from firms, and $T_{t}$ is a lump sum tax. The first order conditions for the household problem are:

$$
\begin{gathered}
\lambda_{t}=U_{C} \\
-U_{N}=\lambda_{t} w_{t} \\
\lambda_{t}=\beta\left(1+i_{t}\right) E_{t} \lambda_{t+1}\left(1+\pi_{t+1}\right)^{-1}
\end{gathered}
$$

Equation (1) shows that the marginal utility of consumption equals the Lagrange multiplier on the flow budget constraint, which we denote by $\lambda_{t}$. The standard static labor supply first order

condition is given by (2). The Euler equation for bonds is given by (3), where $1+\pi_{t}=\frac{P_{t}}{P_{t-1}}$ is the inflation rate.

\section{$2.2 \quad$ Firms}

Production is broken into two sectors. There exist a continuum of firms indexed by $j \in[0,1]$ who produce output, $Y_{t}(j)$. This differentiated output is transformed into aggregate output, $Y_{t}$, by a competitive final goods firm using the bundler: 


$$
Y_{t}=\left(\int_{0}^{1} Y_{t}(j)^{\frac{\epsilon_{p}-1}{\epsilon_{p}}} d j\right)^{\frac{\epsilon_{p}}{\epsilon_{p}-1}}, \quad \epsilon_{p}>1
$$

The parameter $\epsilon_{p}$ denotes the elasticity of substitution among different goods. Profit maximization yields a downward-sloping demand for each variety and an aggregate price index:

$$
\begin{aligned}
Y_{t}(j) & =\left(\frac{P_{t}(j)}{P_{t}}\right)^{-\epsilon_{p}} Y_{t} \\
P_{t}^{1-\epsilon_{p}} & =\int_{0}^{1} P_{t}(j)^{1-\epsilon_{p}} d j
\end{aligned}
$$

The production function for producers of differentiated goods is linear in labor input, subject to a common productivity disturbance, $A_{t}$ :

$$
Y_{t}(j)=A_{t} N_{t}(j)
$$

Firms have some market-power in setting the price of their own good, but are price-takers in the market for labor. Cost-minimization implies that all firms face the same real marginal cost, equal to the ratio of the real wage to the marginal product of labor:

$$
m c_{t}=\frac{w_{t}}{A_{t}}
$$

Firms are not freely able to adjust their price each period. There is a $1-\theta_{p}, \theta_{p} \in[0,1)$, probability that a firm can change its price in a period. Non-updated prices can be indexed to lagged inflation at $\zeta_{p} \in[0,1]$. Thus, a firm's price in period $t$ is given by:

$$
P_{t}(j)= \begin{cases}P_{t}^{\#}(j) & \text { if } P_{t}(j) \text { chosen optimally } \\ \left(1+\pi_{t-1}\right)^{\zeta_{p}} P_{t-1}(j) & \text { otherwise }\end{cases}
$$

Firms given the opportunity to update their price will do so to maximize the present discounted value of flow profits, where discounting is by the stochastic discount factor of the household as well as the probability that a price chosen in period $t$ will still be charged in the future. It is straightforward to show that all updating firms will choose the same reset price, $P_{t}^{\#}$. Letting $1+\pi_{t}^{\#}=\frac{P_{t}^{\#}}{P_{t-1}}$ denote reset price inflation, the optimality conditions for updated prices are:

$$
\begin{gathered}
\frac{1+\pi_{t}^{\#}}{1+\pi_{t}}=\frac{\epsilon_{p}}{\epsilon_{p}-1} \frac{x_{1, t}}{x_{2, t}} \\
x_{1, t}=\lambda_{t} m c_{t} Y_{t}+\theta_{p} \beta E_{t}\left(1+\pi_{t}\right)^{-\zeta_{p} \epsilon_{p}}\left(1+\pi_{t+1}\right)^{\epsilon_{p}} x_{1, t+1} \\
x_{2, t}=\lambda_{t} Y_{t}+\theta_{p} \beta E_{t}\left(1+\pi_{t}\right)^{\zeta_{p}\left(1-\epsilon_{p}\right)}\left(1+\pi_{t+1}\right)^{\epsilon_{p}-1} x_{2, t+1}
\end{gathered}
$$




\subsection{Policy}

Monetary policy is set according to a standard Taylor-type rule in which the interest rate reacts to deviations of inflation from an exogenous target, $\pi^{*}$, and to output growth. The exogenous variable $e_{i, t}$ is a shock to the monetary policy rule and follows a standard normal distribution, with $s_{i}$ the standard deviation of the shock. The steady state nominal interest rate is $1+i^{*}=\beta^{-1}\left(1+\pi^{*}\right)$ :

$$
i_{t}=\left(1-\rho_{i}\right) i^{*}+\rho_{i} i_{t-1}+\left(1-\rho_{i}\right)\left(\phi_{\pi}\left(\pi_{t}-\pi^{*}\right)+\phi_{y}\left(\ln Y_{t}-\ln Y_{t-1}\right)\right)+s_{i} e_{i, t}
$$

The parameter $0 \leq \rho_{i}<1$ is a smoothing parameter, and $\phi_{\pi}$ and $\phi_{y}$ are non-negative coefficients. We restrict attention to parameter configurations supporting a determinate equilibrium. We assume that the government issues no debt and balances its budget each period with lump sum taxes.

$$
G_{t}=T_{t}
$$

Government spending is assumed to follow a stationary $\operatorname{AR}(1)$ process in the log, with $G^{*}$ the steady state level of spending. The exogenous shock $e_{g, t}$ is drawn from a standard normal distribution with standard deviation $s_{g}$ :

$$
\ln G_{t}=\left(1-\rho_{g}\right) \ln G^{*}+\rho_{g} \ln G_{t-1}+s_{g} e_{g, t}, \quad 0 \leq \rho_{g}<1
$$

\subsection{Market-Clearing and Equilibrium}

Market-clearing requires that the household holds no bonds, that total labor demanded by firms equals household labor supply, and that firms produce sufficient output to meet demand at their price. These conditions give rise to a standard aggregate resource constraint and production function:

$$
\begin{gathered}
Y_{t}=C_{t}+G_{t} \\
Y_{t}=\frac{A_{t} N_{t}}{v_{t}^{p}}
\end{gathered}
$$

In the production function, $v_{t}^{p}$ is a measure of price dispersion which potentially drives a wedge between aggregate labor supply and labor used in production by firms. It can be written recursively in terms of inflation rates:

$$
v_{t}^{p}=\left(1+\pi_{t}\right)^{\epsilon_{p}}\left(\left(1-\theta_{p}\right)\left(1+\pi_{t}^{\#}\right)^{-\epsilon_{p}}+\theta_{p}\left(1+\pi_{t-1}\right)^{-\epsilon_{p} \zeta_{p}} v_{t-1}^{p}\right)
$$

Using properties of Calvo pricing, the expression for the aggregate price level, (6), can be written in terms of inflation rates:

$$
\left(1+\pi_{t}\right)^{1-\epsilon_{p}}=\left(1-\theta_{p}\right)\left(1+\pi_{t}^{\#}\right)^{1-\epsilon_{p}}+\theta_{p}\left(1+\pi_{t-1}\right)^{\zeta_{p}\left(1-\epsilon_{p}\right)}
$$


We assume that the exogenous processes for productivity, $A_{t}$, is stationary mean zero $\operatorname{AR}(1)$ processes in the log:

$$
\ln A_{t}=\rho_{a} \ln A_{t-1}+s_{a} e_{a, t}, \quad 0 \leq \rho_{a}<1
$$

Given initial values of endogenous state variables, equations (1)-(3), (8), (10)-(12), (13), and (15)-(20), in conjunction with the usual transversality conditions, determine the values of $\left\{\lambda_{t}, C_{t}, N_{t}\right.$, $\left.G_{t}, w_{t}, i_{t}, \pi_{t}, m c_{t}, A_{t}, \pi_{t}^{\#}, x_{1, t}, x_{2, t}, Y_{t}, v_{t}^{p}\right\}$.

Since there is a representative household, we can define aggregate welfare, $\mathbb{W}_{t}$, recursively as the expected presented discounted value of flow utility, given optimally chosen sequences of consumption and labor and the exogenous sequence of government spending:

$$
\mathbb{W}_{t}=U\left(C_{t}, N_{t}, G_{t}\right)+\beta E_{t} \mathbb{W}_{t+1}
$$

\subsection{The Output and Welfare Multipliers}

We can derive expressions for the "output multiplier," $\frac{d Y_{t}}{d G_{t}}$, and the "welfare multiplier," $\frac{d \mathbb{W}_{t}}{d G_{t}}$, by totally differentiating the equilibrium conditions about a point (not necessarily the non-stochastic steady state). The output multiplier is commonly referred to as the fiscal multiplier; we will typically refer to it as the output multiplier since it is our objective to differentiate between the output and welfare effects of government spending shocks.

The expressions for the output and welfare multipliers are given below. Variables without subscripts denote the point about which the approximation is taken, and it is understood that the partial derivative functions are dependent on the values of the relevant variables. A complete derivation and some further discussion is available in the Appendix.

$$
\begin{gathered}
\frac{d Y_{t}}{d G_{t}}=\underbrace{\left[\frac{-U_{C C} m c A}{-U_{N N} \frac{v^{p}}{A}-U_{C C} m c A}\right]}_{\text {Efficiency }}+\underbrace{\left[\frac{U_{C} A}{-U_{N N} \frac{v^{p}}{A}-U_{C C} m c A}\right] \frac{d m c_{t}}{d G_{t}}}_{\text {Inefficiency }}+\underbrace{\left[\frac{U_{N N} N}{-U_{N N} \frac{v^{p}}{A}-U_{C C} m c A}\right] \frac{d \ln v_{t}^{p}}{d G_{t}}}_{\text {Price Dispersion }} \\
\frac{d \mathbb{W}_{t}}{d G_{t}}=E_{t} \sum_{j=0}^{\infty} \beta^{t} \frac{d U_{t+j}}{d G_{t+j}} \\
\frac{d U_{t}}{d G_{t}}=\underbrace{\left[U_{G}-U_{C}\right]}_{\text {Efficiency }}+\underbrace{\left[U_{C}+U_{N} \frac{v^{p}}{A}\right] \frac{d Y_{t}}{d G_{t}}}_{\text {Inefficiency }}+\underbrace{\left[U_{N} N\right] \frac{d \ln v_{t}^{p}}{d G_{t}}}_{\text {Price Dispersion }}
\end{gathered}
$$

The welfare multiplier, (23), is simply the expected present discounted value of current and future "utility multipliers," given by (24). For building intuition, it suffices to focus on the effect of changes in government spending on flow utility. There are multiple different ways one might express these multipliers. In our presentation, the expressions for both the output and utility multipliers are split into three additive components. We refer to these different components as "Efficiency," "Inefficiency," and "Price Dispersion," respectively. The efficiency terms show what 
each multiplier would equal if prices were flexible and the equilibrium allocation were efficient; in an efficient, flexible price allocation, real marginal cost and price dispersion would both be one at all times. ${ }^{2}$ The inefficiency terms capture the fact that the equilibrium in the sticky price NK model is distorted, and that changes in government spending can affect both output and utility by altering the level of distortion in the economy. The price dispersion term captures how changes in government spending impact output and utility through an effect on price dispersion.

Focus first on the expression for the output multiplier, (22). If the allocation were efficient, the inefficiency and price dispersion terms would both be zero, leaving only the efficiency term. Given assumptions on preferences, this term must be positive and less than one. If we consider instead an inefficient allocation in which prices are sticky, the terms involving the reactions of real marginal cost and price dispersion to changes in government spending become relevant. Since the term multiplying $\frac{d m c_{t}}{d G_{t}}$ is positive, an increase in government spending that increases real marginal cost results in a larger output multiplier relative to the flexible price case. How exactly marginal cost reacts to a change in government spending is of course dependent on the exact nature of the monetary policy rule; for most plausible specifications of monetary policy, marginal cost rises when government spending increases. This means that the output multiplier ought to be bigger the stickier are prices. Considering now the price dispersion component, we see that the term multiplying the response of log price dispersion to government spending is negative. This means that if an increase in government spending raises price dispersion then the output multiplier would be smaller than if price dispersion were fixed. For most plausible specifications of monetary policy, increases in government spending will raise the inflation rate. In an inflationary state, an increase in inflation raises price dispersion, while the reverse would be true in a deflationary state. In the region of a zero inflation state, $d \ln v_{t}^{p} \approx 0$, and this term could be ignored altogether.

It is not particularly straightforward to use (22) to make any concrete predictions about how the output multiplier will vary across states. Any state-dependence of the output multiplier will depend on the third derivatives of the utility function, $U_{C C C}$ and $U_{N N N}$, as well as any non-linear reactions of real marginal cost and price dispersion to changes in government spending. The reactions of real marginal cost and price dispersion in turn depend on the monetary policy rule as well as other details of the model. We leave it as an open quantitative question for the next section how (if at all) the output multiplier moves across states.

Focus next on the expression for the utility multiplier, (24). The first term is simply the difference between the marginal utilities of government spending and private consumption, and is what the utility multiplier would equal in an efficient allocation. The second term is the product of the output multiplier and a term which measures the level of inefficiency in the economy. If the allocation were efficient, then the marginal utility of consumption would equal the marginal utility of labor divided by the marginal product of labor, and this term would equal zero. In the NK model absent some kind of tax subsidy, the equilibrium allocation is inefficient due to monopolistic competition and price rigidity, so this term will typically be positive. The final term is a function of the reaction of price dispersion to a change in government spending. Given assumptions on

\footnotetext{
${ }^{2}$ This would obtain if $\epsilon_{p} \rightarrow \infty$ (so that firms have no market power) and $\theta_{p}=0$ (so that prices are fully flexible).
} 
preferences, the term multiplying the reaction of price dispersion is negative.

Without knowing the function mapping government spending into utility, it is impossible to sign the utility multiplier - it could be highly positive if $G_{t}$ is very low or negative if $G_{t}$ is high. We can, however, use this expression to think about state-dependence in the utility multiplier. In recessions the marginal utility of consumption is high. Other things being equal, this would, through the efficiency term, tend to make the utility multiplier relatively low in a recession and high in an expansion, i.e. procyclical. Focus next on the inefficiency term. Empirically, the US economy appears to be relatively inefficient in recessions (i.e. the labor wedge, as defined in Chari, Kehoe, and McGrattan, 2007, is countercylical). This would tend to make the term $U_{C}+U_{N} \frac{v^{p}}{A}$ relatively big in a downturn. Since the output multiplier is positive, this countercylical level of inefficiency would work in the opposite direction of the efficiency term, working to make the utility multiplier countercyclical. Also, given a positive value of $U_{C}+U_{N} \frac{v^{p}}{A}$, any state-dependence in the output multiplier would work to make the utility multiplier move in the same direction as the output multiplier. Finally, the price dispersion term would have effects on the utility multiplier similar as in the case of the output multiplier. In the region of a zero inflation state, price dispersion is second order and this term equals zero. In an inflationary state, increases in government spending will raise price dispersion which would work to lower the utility multiplier and vice-versa.

Given the different forces at work it is difficult to draw any concrete general conclusions from these analytic expressions for the output and utility multipliers. It is ultimately a quantitative question as to how much (if at all) these multipliers vary over the business cycle, a task we take up next in a more empirically realistic version of this model with capital accumulation and several other features. Before proceeding, we can, however, use these analytic expressions to make a few predictions. First, if the allocation is close to efficient, then the utility multiplier (and hence the welfare multiplier) ought to be procyclical. Second, the utility multiplier (and hence the welfare multiplier), will be less procyclical (i) the more countercyclical is the overall level of distortion in the economy, (ii) the bigger is the output multiplier, and (iii) the more countercyclical is the output multiplier. Third, through the dispersion terms, one might expect both the output and welfare multipliers to co-vary negatively with the inflation rate; though some caution is in order with this conclusion, as the inflation rate might be correlated with other terms in the expressions not related to the dispersion effect. Fourth, the co-movement of the welfare multiplier with output ought to depend on the kind of shock responsible for output being high or low. In particular, we would expect adverse "demand shocks" to be associated with low output, a relatively inefficient allocation, and low inflation. ${ }^{3}$ A relatively inefficient allocation would mean that the "Inefficiency" term in the utility multiplier expression would be relatively strong, while low inflation means that the inflation generated by an increase in government spending would lower price dispersion. Both of these effects would tend to make the welfare multiplier relatively high when output is low. The reverse would be true if output is low due to adverse "supply shocks." We would therefore expect the welfare multiplier to be most procyclical conditional on supply shocks and less so conditional

\footnotetext{
${ }^{3}$ We adopt the common terminology and think of a "demand shock" as a shock which moves output and inflation in the same direction and a "supply shock" as a shock which moves output and inflation in opposite directions.
} 
on demand shocks.

\section{A Medium Scale DSGE Model}

This section considers a "medium scale" dynamic stochastic general equilibrium (DSGE) model, similar to the models in Christiano, Eichenbaum, and Evans (2005) and Smets and Wouters (2007). The model can be thought of as an extension of the simple NK model in the previous section to include capital, wage rigidity, some sources of real inertia, and several more shocks. The model also allows for a more general treatment of fiscal finance. Where different from the simpler model, we describe the decision problems and optimality conditions characterizing the equilibrium. We then estimate the model using Bayesian maximum likelihood so as to have a realistic parameter configuration before quantitatively investigating the state-dependence of the output and welfare multipliers.

\subsection{Households}

Rather than a representative household as in Section 2, there exist a continuum of households indexed by $h \in[0,1]$. These households supply differentiated labor to a labor "bundling" firm which produces a homogeneous labor input that is used in production. The technology which bundles heterogenous labor input is given by:

$$
N_{t}=\left(\int_{0}^{1} N_{t}(h)^{\frac{\epsilon_{w}-1}{\epsilon_{w}}} d h\right)^{\frac{\epsilon_{w}}{\epsilon_{w}-1}}, \quad \epsilon_{w}>1
$$

$N_{t}(h)$ denotes labor from household $h$ and $N_{t}$ is aggregate labor input. The parameter $\epsilon_{w}>1$ is the elasticity of substitution among different varieties of labor. Profit-maximization gives rise to a downward-sloping demand curve for each variety of labor:

$$
N_{t}(h)=\left(\frac{w_{t}(h)}{w_{t}}\right)^{-\epsilon_{w}} N_{t}
$$

Here $w_{t}(h)$ is the real wage charge by household $h$ and $w_{t}$ is the aggregate real wage. The zero profit-condition for the labor bundler implies an aggregate real wage index:

$$
w_{t}^{1-\epsilon_{w}}=\int_{0}^{1} w_{t}(h)^{1-\epsilon_{w}} d h
$$

Households have identical preferences which are additively separable in consumption, labor, and government spending, the latter of which the households take as given. Households are subject to Calvo type wage rigidity as in Erceg, Henderson, and Levin (2000). Each period, there is a $1-\theta_{w}$ probability that a household can adjust its nominal wage, with $\theta_{w} \in[0,1)$. Non-updated wages may be indexed to lagged inflation at $\zeta_{w} \in[0,1]$. We assume that households have access to a full set of state-contingent securities which insure them against idiosyncratic wage risk arising from imperfect wage flexibility. Given separability between consumption and labor, this means that all 
households will make identical non-labor choices. As such, we suppress formal dependence on $h$ in writing the household problem with the exception of labor and wage variables. The fact that preferences are separable in government spending implies that while government spending affects utility, the manner in which it does so will be irrelevant for household behavior and equilibrium allocations.

The household problem can be written:

$$
\begin{gathered}
\max _{C_{t}, I_{t}, u_{t}, K_{t+1}, B_{t}, w_{t}(h), N_{t}(h)} E_{0} \sum_{t=0}^{\infty} \beta^{t} \nu_{t}\left\{\ln \left(C_{t}-b C_{t-1}\right)-\psi \xi_{t} \frac{N_{t}(h)^{1+\chi}}{1+\chi}+\varphi G_{t}\right\} \\
\text { s.t. } \\
\left(1+\tau_{t}^{c}\right) C_{t}+I_{t}+\frac{B_{t}}{P_{t}} \leq\left(1-\tau_{t}^{k}\right) R_{t} u_{t} K_{t}+\left(1-\tau_{t}^{n}\right) w_{t}(h) N_{t}(h)+\Pi_{t}-T_{t}+\left(1+i_{t-1}\right) \frac{B_{t-1}}{P_{t}} \\
K_{t+1}=Z_{t}\left[1-S\left(\frac{I_{t}}{I_{t-1}}\right)\right] I_{t}+\left(1-\delta\left(u_{t}\right)\right) K_{t} \\
N_{t}(h)=\left(\frac{w_{t}(h)}{w_{t}}\right)^{-\epsilon_{w}} N_{t} \\
w_{t}(h)= \begin{cases}w_{t}^{\#}(h) & \text { if } w_{t}(h) \text { chosen optimally } \\
\left(1+\pi_{t-1}\right)^{\zeta_{w}}\left(1+\pi_{t}\right)^{-1} w_{t-1}(h) & \text { otherwise }\end{cases}
\end{gathered}
$$

The household discounts future utility flows by $\beta \in(0,1)$. The parameter $b \in[0,1)$ is a measure of internal habit formation. The Frisch labor supply elasticity is given by the inverse of $\chi \geq 0$, and $\psi>0$ is a scaling parameter. The parameter $\varphi \geq 0$ scales the utility households receive from government spending. We assume that government spending enters utility linearly. ${ }^{4}$ The exogenous variables $\nu_{t}$ and $\xi_{t}$ are preference shocks with mean one, the former an intertemporal preference shock which impacts the relative discounting of future utility flows and the latter a labor supply shock.

The flow budget constraint is given by (28). Consumption is denoted by $C_{t}$, physical capital by $K_{t}$, investment in new physical capital by $I_{t}$, and utilization of capital by $u_{t}$. The household enters a period with a stock of nominal bonds, $B_{t-1}$, which pay out nominal interest rate $i_{t-1}$. The price level is $P_{t}$. Households lease capital services, the product of utilization and physical capital, to firms at competitive real rental rate $R_{t}$. Lump sum profit distributed to households by firms is given by $\Pi_{t}$, while $T_{t}$ is a lump sum tax paid to the government. The variables $\tau_{t}^{c}, \tau_{t}^{k}$, and $\tau_{t}^{n}$ are distortionary and potentially time-varying consumption, capital, and labor taxes, respectively.

The capital accumulation equation is given by (29). The exogenous variable $Z_{t}$ is an exogenous shock to the marginal efficiency of investment. $S(\cdot)$ is an investment adjustment cost as in Christiano, Eichenbaum, and Evans (2005) and $\delta(\cdot)$ is a time-varying depreciation rate on capital as a function of utilization. We assume that these functions are given by:

\footnotetext{
${ }^{4}$ We have also experimented with allowing curvature in the function mapping government spending into utility. This has very little effect on the co-movements of the welfare multiplier across states. The reason is simple - in the data, government spending is not very volatile and acylical, so assuming a constant marginal utility of government spending is fairly innocuous.
} 


$$
\begin{gathered}
S\left(\frac{I_{t}}{I_{t-1}}\right)=\frac{\kappa}{2}\left(\frac{I_{t}}{I_{t-1}}-1\right)^{2}, \quad \kappa \geq 0 \\
\delta\left(u_{t}\right)=\delta_{0}+\delta_{1}\left(u_{t}-1\right)+\frac{\delta_{2}}{2}\left(u_{t}-1\right)^{2}, \quad \delta_{0}, \delta_{1}, \delta_{2}>0
\end{gathered}
$$

Constraint (30) requires that a household's labor supply meet demand, given the household's real wage, $w_{t}(h)$. Constraint $(31)$ describes wage-setting. The variable $w_{t}(h)^{\#}$ is the optimal wage that a household given the opportunity to adjust its wage would choose. For non-labor choices, the optimality conditions, which are common across all households, are:

$$
\begin{gathered}
\left(1+\tau_{t}^{c}\right) \lambda_{t}=\nu_{t} \frac{1}{C_{t}-b C_{t-1}}-\beta b E_{t} \nu_{t+1} \frac{1}{C_{t+1}-b C_{t}} \\
\lambda_{t}=\beta\left(1+i_{t}\right) E_{t} \lambda_{t+1}\left(1+\pi_{t+1}\right)^{-1} \\
\left(1-\tau_{t}^{k}\right) \lambda_{t} R_{t}=\mu_{t}\left(\delta_{1}+\delta_{2}\left(u_{t}-1\right)\right) \\
\mu_{t}=\beta E_{t}\left[\lambda_{t+1}\left(1-\tau_{t+1}^{k}\right) R_{t+1} u_{t+1}+\left(1-\delta\left(u_{t+1}\right)\right) \mu_{t+1}\right] \\
\lambda_{t}=\mu_{t} Z_{t}\left[1-\frac{\kappa}{2}\left(\frac{I_{t}}{I_{t-1}}-1\right)^{2}-\kappa\left(\frac{I_{t}}{I_{t-1}}-1\right) \frac{I_{t}}{I_{t-1}}\right]+\beta E_{t} \mu_{t+1} Z_{t+1} \kappa\left(\frac{I_{t+1}}{I_{t}}-1\right)\left(\frac{I_{t+1}}{I_{t}}\right)^{2}
\end{gathered}
$$

In these conditions $\lambda_{t}$ is the Lagrange multiplier on the flow budget constraint and $\mu_{t}$ is the multiplier on the capital accumulation equation. In terms of labor supply and wage-setting, it is straightforward to show that all households given the opportunity will adjust to the same real wage, $w_{t}^{\#}$. It is given by:

$$
\begin{gathered}
w_{t}^{\#}=\frac{\epsilon_{w}}{\epsilon_{w}-1} \frac{f_{1, t}}{f_{2, t}} \\
f_{1, t}=\nu_{t} \xi_{t} \psi\left(\frac{w_{t}}{w_{t}^{\#}}\right)^{\epsilon_{w}(1+\chi)} N_{t}^{1+\chi}+\beta \theta_{w} E_{t}\left(\frac{w_{t+1}^{\#}}{w_{t}^{\#}}\right)^{\epsilon_{w}(1+\chi)}\left(\frac{\left(1+\pi_{t}\right)^{\zeta_{w}}}{1+\pi_{t+1}}\right)^{-\epsilon_{w}(1+\chi)} f_{1, t+1} \\
f_{2, t}=\lambda_{t}\left(1-\tau_{t}^{n}\right)\left(\frac{w_{t}}{w_{t}^{\#}}\right)^{\epsilon_{w}} N_{t}+\beta \theta_{w} E_{t}\left(\frac{w_{t+1}^{\#}}{w_{t}^{\#}}\right)^{\epsilon_{w}}\left(\frac{\left(1+\pi_{t}\right)^{\zeta_{w}}}{1+\pi_{t+1}}\right)^{1-\epsilon_{w}} f_{2, t+1}
\end{gathered}
$$

\section{$3.2 \quad$ Firms}

As in the simpler model, production is broken into two sectors, with a representative final goods producer and a continuum of intermediate producers indexed by $j \in[0,1]$. The final goods sector is identical to the simpler model, generating the same downward-sloping demand for each variety of intermediate good, (5), and the price index, (6).

The production function for the producer of variety $j$ is given by:

$$
Y_{t}(j)=\max \left\{A_{t} \widehat{K}_{t}(j)^{\alpha} N_{t}(j)^{1-\alpha}-F, 0\right\}, \quad 0<\alpha<1
$$


This production function differs from the simpler model along three dimensions: (i) capital services, $\widehat{K}_{t}$, or the product of physical capital and utilization, is a factor of production; (ii) there are diminishing returns in labor; and (iii) there is a fixed cost to production, $F$. $A_{t}$ is again an exogenous productivity shock common to all firms. These firms are price-takers in the markets for labor and capital services. Cost-minimization implies that all firms have the same real marginal cost and hire capital services and labor in the same ratio:

$$
\begin{gathered}
m c_{t}=\frac{w_{t}^{1-\alpha} R_{t}^{\alpha}}{A_{t}}(1-\alpha)^{\alpha-1} \alpha^{-\alpha} \\
\frac{\widehat{K}_{t}}{N_{t}}=\frac{\alpha}{1-\alpha} \frac{w_{t}}{R_{t}}
\end{gathered}
$$

Firms are not freely able to adjust their price in each period in exactly the same way as in the simpler model. The pricing problem and optimal decision rules are identical to that setup, given by equations (9)-(12) from the previous section.

\subsection{Policy}

We assume that monetary policy is characterized by the same Taylor rule as in the previous section, (13). Different from the simpler model, we allow for a more general treatment of fiscal finance. The government budget constraint is:

$$
G_{t}+i_{t-1} \frac{B_{g, t-1}}{P_{t}}=\tau_{t}^{c} C_{t}+\int_{0}^{1} \tau_{t}^{n} w_{t}(h) N_{t}(h) d h+\tau_{t}^{k} R_{t} \widehat{K}_{t}+T_{t}+\frac{B_{g, t}}{P_{t}}-\frac{B_{g, t-1}}{P_{t}}
$$

$B_{g, t-1}$ is the stock of nominal debt with which the government enters period $t$. We define $b_{g, t}=\frac{B_{g, t}}{P_{t}}$ as real debt. Government expenditure plus interest payments on outstanding debt must equal tax collections plus issuance of new debt. The tax instruments follow AR(1) processes with a non-negative response to the deviation of real government debt from an exogenous long run target level, $b_{g}^{*}$. We assume that there are no exogenous shocks to the tax rates. Some or all of the tax instruments must react sufficiently to debt so as to satisfy a condition that the path of government debt be non-explosive:

$$
\begin{gathered}
\tau_{t}^{c}=\left(1-\rho_{c}\right) \tau^{c}+\rho_{c} \tau_{t-1}^{c}+\left(1-\rho_{c}\right) \gamma_{c}\left(b_{g, t-1}-b_{g}^{*}\right) \\
\tau_{t}^{n}=\left(1-\rho_{n}\right) \tau^{n}+\rho_{n} \tau_{t-1}^{n}+\left(1-\rho_{n}\right) \gamma_{n}\left(b_{g, t-1}-b_{g}^{*}\right) \\
\tau_{t}^{k}=\left(1-\rho_{k}\right) \tau^{k}+\rho_{k} \tau_{t-1}^{k}+\left(1-\rho_{k}\right) \gamma_{k}\left(b_{g, t-1}-b_{g}^{*}\right) \\
T_{t}=\left(1-\rho_{T}\right) T++\rho_{T} T_{t-1}+\left(1-\rho_{T}\right) \gamma_{T}\left(b_{g, t-1}-b_{g}^{*}\right)
\end{gathered}
$$

$\tau^{c}, \tau^{n}, \tau^{k}$, and $T$ are the steady state values of the tax rates. The autoregressive parameters are restricted such that $0 \leq \rho_{l}<1$, for $l=c, n, k, T$, and the coefficients on lagged debt must be non-negative, $\gamma_{l} \geq 0$, for $l=c, n, k, T$. Government spending is assumed to follow the same stationary $\mathrm{AR}(1)$ process in the log as in the simpler model, given by (15). 


\subsection{Market-Clearing and Equilibrium}

Market-clearing requires that households hold all government debt and that firms meet demand at their prices. These conditions give rise to a standard aggregate resource constraint and production function: ${ }^{5}$

$$
\begin{gathered}
Y_{t}=C_{t}+I_{t}+G_{t} \\
Y_{t}=\frac{A_{t} \widehat{K}_{t}^{\alpha} N_{t}^{1-\alpha}}{v_{t}^{p}}
\end{gathered}
$$

In the production function $v_{t}^{p}$ is a measure of price dispersion which potentially drives a wedge between aggregate factor supply and factors used in production by firms. It is given by the same process as in the simpler model of Section 2, (18). The expression for the evolution of aggregate inflation is also the same as in the simpler model, given by (19). $\widehat{K}_{t}$ is the aggregate supply of capital services and is given by:

$$
\widehat{K}_{t}=u_{t} K_{t}
$$

Using properties of Calvo wage-setting, the real wage index can be written:

$$
w_{t}^{1-\epsilon_{w}}=\left(1-\theta_{w}\right) w_{t}^{\#, 1-\epsilon_{w}}+\theta_{w}\left(\frac{\left(1+\pi_{t-1}\right)^{\zeta_{w}}}{1+\pi_{t}} w_{t-1}\right)^{1-\epsilon_{w}}
$$

Given the demand curve for each variety of labor and the real wage index, the integral in the government budget constraint can be eliminated, leaving:

$$
G_{t}+i_{t-1} b_{g, t-1}\left(1+\pi_{t}\right)^{-1}=\tau_{t}^{c} C_{t}+\tau_{t}^{n} w_{t} N_{t}+\tau_{t}^{k} R_{t} \widehat{K}_{t}+T_{t}+b_{g, t}-b_{g, t-1}\left(1+\pi_{t}\right)^{-1}
$$

We assume that process for exogenous productivity is the same as in the simpler model, (20). We assume that the investment shock, $Z_{t}$, and the two preference shocks, $\nu_{t}$ and $\xi_{t}$, all follow stationary mean zero $\mathrm{AR}(1)$ processes in the log:

$$
\begin{array}{ll}
\ln Z_{t}=\rho_{z} \ln Z_{t-1}+s_{z} e_{z, t}, & 0 \leq \rho_{z}<1 \\
\ln \nu_{t}=\rho_{\nu} \ln \nu_{t-1}+s_{\nu} e_{\nu, t}, & 0 \leq \rho_{\nu}<1 \\
\ln \xi_{t}=\rho_{\xi} \ln \xi_{t-1}+s_{\xi} e_{\xi, t}, & 0 \leq \rho_{\xi}<1
\end{array}
$$

In total, the model has six stochastic shocks - shocks to productivity; the marginal efficiency of

\footnotetext{
${ }^{5}$ It is common to model the cost of capital utilization as a resource cost, for example as in Christiano, Eichenbaum, and Evans (2005), as opposed to faster depreciation as we do here. Earlier versions of this paper used the resource cost specification and our results concerning state-dependence are similar. The advantage of this specification, aside from being more consistent with the NIPA accounts, is that the output multiplier cannot exceed unity if the sum of consumption and investment does not rise after an increase in government spending, which is not true when utilization appears in the aggregate resource constraint.
} 
investment; an intertemporal preference shock, $\nu_{t}$; an intratemporal labor supply shock, $\xi_{t}$; a monetary policy shock, and the government spending shock. Given initial values of the endogenous state variables, equations (10)-(13), (15), (18)-(20), (29), (34)-(41), (43)-(44), (46)-(52), and (53)-(57), along with the usual transversality conditions, determine the values of $\left\{C_{t}, I_{t}, u_{t}, K_{t}, G_{t}, \nu_{t}, \xi_{t}, \tau_{t}^{c}, \tau_{t}^{n}\right.$, $\left.\tau_{t}^{k}, R_{t}, i_{t}, \pi_{t}, \lambda_{t}, \mu_{t}, w_{t}^{\#}, w_{t}, N_{t}, f_{1, t}, f_{2, t}, m c_{t}, \widehat{K}_{t}, \pi_{t}^{\#}, x_{1, t}, x_{2, t}, T_{t}, b_{g, t}, Y_{t}, v_{t}^{p}, Z_{t}, A_{t}\right\}$.

\subsection{Estimation}

Our approach is to first calibrate a number of parameters that are closely tied to long run moments of the data. We then estimate the remaining parameters via Bayesian maximum likelihood.

As a benchmark, we assume that all distortionary taxes are constant at zero, which implies that the exact mix between lump sum tax and bond finance is irrelevant. We can thus ignore the parameters governing the tax processes altogether, and do not need to specify the steady state level of government debt. ${ }^{6}$ While this is undoubtedly unrealistic, it is fairly common to ignore distortionary tax rates in estimation of medium scale DSGE models. We will consider robustness to different financing regimes below.

Other calibrated parameters include $\left\{\beta, \alpha, \delta_{0}, \delta_{1}, \delta_{2}, \epsilon_{p}, \epsilon_{w}, \psi, \pi^{*}, F, G^{*}\right\}$. These values are shown in Table 1 . We set $\beta=0.995$ and $\alpha=1 / 3$. The elasticity of substitution among goods and labor are set to $\epsilon_{p}=\epsilon_{w}=11$, which implies steady state price and wage markups of 10 percent. We set $\delta_{0}=0.025$ and then pick $\delta_{1}$ so as to normalize steady state utilization to unity. We set $\delta_{2}=0.01$, which implies that utilization is highly volatile and is consistent with a number of other studies. The scaling parameter on the disutility of labor is set to $\psi=6$, which implies steady state labor hours between 0.3 and 0.5 for plausible values of other parameters; to first order, this parameter is irrelevant for dynamics and only serves to scale variables. We assume zero trend inflation; alternatively, we could have assumed complete wage and price indexation to a non-zero level of trend inflation. The fixed cost, $F$, is set so that profits are zero in steady state. The steady state value of government spending is chosen so that the the steady state ratio of government spending to output is 0.20 . Because utility from government spending is additively separable, the parameter $\varphi$ is irrelevant for equilibrium dynamics and need not be specified for the estimation.

The remaining parameters are estimated using Bayesian maximum likelihood. The observable variables in our estimation are the quarterly growth rates of output, consumption, and hours worked per capita, as well as the levels of the inflation rate, the nominal interest rate, and the government-spending output ratio. Nominal output is defined as the headline NIPA number, nominal consumption is constructed as the the sum of non-durables and services consumption, and nominal government spending is measured as government consumption expenditures and gross investment. We use the GDP implicit price deflator to transform the nominal series into real, and also divide by the civilian non-institutionalized population aged sixteen and over to put them in per capita terms. The inflation rate is defined as the log first difference of the GDP deflator. The

\footnotetext{
${ }^{6}$ Without distortionary taxes it is without loss of generality to set $T_{t}=G_{t}$, so that none of the parameters of the lump sum tax processes need be given values.
} 
hours series is total hours worked in the non-farm business sector expressed in per capita units. The interest rate is measured by the three month Treasury Bill rate. The sample period is 1984q12008q3. The beginning date is chosen because of the sharp break in volatility in the early 1980s associated with the "Great Moderation" while the end date is chosen so as to exclude the zero lower bound period.

The prior and posterior distributions of the estimated parameters are shown in Table 2. Overall the estimated parameters seem quite reasonable and are generally in line with the existing literature. The estimated model generates second moments that are close to their empirical counterparts. In terms of accounting for business cycle dynamics, the shock to the marginal efficiency of investment is the most important shock, accounting for 55 percent of the unconditional variance of output growth. This is in line with Justiniano, Primiceri, and Tambalotti (2010). The productivity shock is much less important, accounting for a little less than 10 percent of the variance of output growth. The labor supply preference shock explains about 25 percent of the variance of output growth. The intertemporal preference and government spending shocks each account for roughly 5 percent of the variance of output growth. The monetary policy shock accounts for only 1 percent of the unconditional variance of output growth.

\section{Quantitative Analysis}

In this section we conduct quantitative analysis on the estimated model. We compute output and welfare multipliers at different points in the state space and analyze how they vary across the business cycle. We also consider the effects of an interest rate peg (meant to capture the effects of the zero lower bound) as well as different means of government finance.

To compute the welfare multiplier we must first specify a measure of aggregate welfare. Unlike the representative household model in Section 2, this is not completely innocuous because of the heterogeneity among households due to staggered wage-setting. We define welfare at time $t$ for a particular household, $V_{t}(h)$, as the present discounted value of flow utility given optimizing behavior. This can be written recursively:

$$
V_{t}(h)=\nu_{t}\left[\ln \left(C_{t}-b C_{t-1}\right)-\psi \xi_{t} \frac{N_{t}(h)^{1+\chi}}{1+\chi}+\varphi G_{t}\right]+\beta E_{t} V_{t+1}(h)
$$

We define aggregate welfare, $\mathbb{W}_{t}$, as the sum of welfare of across agents, i.e. $\mathbb{W}_{t}=\int_{0}^{1} V_{t}(h) d h$. This can be written in terms of aggregate variables:

$$
\mathbb{W}_{t}=\nu_{t}\left[\ln \left(C_{t}-b C_{t-1}\right)-\psi \xi_{t} v_{t}^{w} \frac{N_{t}^{1+\chi}}{1+\chi}+\varphi G_{t}\right]+\beta E_{t} \mathbb{W}_{t+1}
$$

In this expression $v_{t}^{w}$ is a measure of wage dispersion. It can be written: 


$$
v_{t}^{w}=\left(1-\theta_{w}\right)\left(\frac{w_{t}^{\#}}{w_{t}}\right)^{-\epsilon_{w}(1+\chi)}+\theta_{w}\left(\frac{w_{t-1}}{w_{t}} \frac{\left(1+\pi_{t-1}\right)^{\zeta_{w}}}{1+\pi_{t}}\right)^{-\epsilon_{w}(1+\chi)} v_{t-1}^{w}
$$

When solving the model, we simply include (59) and (60) as equilibrium conditions and analyze how $\mathbb{W}_{t}$ reacts to changes in government spending.

Given the calibrated and estimated parameters from the previous section (we use the mode of the posterior distribution), we solve the model using either a second or third order approximation about the non-stochastic steady state. In a higher order approximation impulse response functions to shocks will depend on the initial value of the state vector, $\mathbf{s}_{t-1}$. We compute impulse responses of output and aggregate welfare to a government spending shock at different points in the state space via simulation. The initial states from which the impulse responses are computed are either the non-stochastic steady state (which can be solved for analytically) or are produced via simulating states using the policy functions. Formally, the impulse response function of a vector of endogenous variables $\mathbf{x}_{t}$ to shock $m$ is $\operatorname{IRF}_{m}(h)=\left\{\mathbf{E}_{t} \mathbf{x}_{t+h}-\mathbf{E}_{t-1} \mathbf{x}_{t+h} \mid \mathbf{s}_{t-1}, \widehat{e}_{m, t}=e_{m, t}+s_{m}\right\}$, where $h \geq 0$ is the forecast horizon. Numerically, we compute the impulse responses as follows. Given an initial value of the state, $\mathbf{s}_{t-1}$, we compute two sets of simulations of the endogenous variables using the same draws of shocks. In one simulation we add $s_{m}$ to the realization of shock $m$ in period $t$. We compute the simulations out to a forecast horizon of $H$, which we set to 20 . We repeat this process $T$ times, average over the realized values of the endogenous variables at forecast horizons up to $H$, and take the difference between the average simulations with and without the extra $s_{m}$ shock in period $t$. We use a value of $T=150$.

The output multiplier, $\frac{d Y_{t}}{d G_{t}}$, is defined as the change in output for a one unit change in government spending. We compute the multiplier by taking the ratio of the impulse response of output on impact to the impact response of government spending to a spending shock ("impact" meaning $h=0)$. For most specifications of the model, the impact response of output corresponds to the largest response to a spending shock at any forecast horizon. The welfare multiplier is defined as $\frac{d \mathbb{W}_{t}}{d G_{t}}$. We compute the welfare multiplier as the impact response of aggregate welfare to the impact response of government spending to a spending shock. To make the units of the welfare multiplier interpretable and comparable to the output multiplier, we divide this by the steady state marginal utility of consumption. This gives the welfare multiplier the interpretation as the units of steady state consumption households would have to be given in one period to produce an equivalent change in welfare as the spending shock. ${ }^{7}$

The parameter $\varphi$, which scales the utility households receive from government spending, is irrelevant for equilibrium output dynamics but is critical in terms of scaling the magnitude of the welfare multiplier. Since there is no way to identify the value of this parameter, we choose its value so as to normalize the welfare multiplier evaluated in the steady state to zero. In this way we can

\footnotetext{
${ }^{7}$ An alternative would be to divide by the marginal utility of consumption at a particular point in the state space. We have done this and our results are similar. Our preference for using the steady state marginal utility of consumption is because the ultimate object of interest is $\frac{d \mathbb{W}_{t}}{d G_{t}}$. The division by marginal utility of consumption is just to re-scale the multiplier and give it more interpretable units, and it makes most sense to re-scale by a fixed factor (steady state marginal utility) as opposed to a time-varying factor (marginal utility in a particular state).
} 
think of government spending as being optimal in the steady state in the sense that a small change in government spending has no effect on welfare. This normalization does not affect any of our results concerning the movements in the welfare multiplier across different states.

\subsection{Baseline Results}

Table 3 shows output and welfare multipliers in three different states. We show these numbers for both a second order and third order approximation. The rows labeled "Steady State" show multipliers when the economy initially sits in the non-stochastic steady state. The rows labeled "Recession" and "Expansion" show multipliers in "typical" recessions and expansions. To generate these states we simulate 10,000 periods and average over realizations of the state when output is in its lower and upper 20th percentiles, respectively. We then compute multipliers starting from these average realizations of the state.

In the non-stochastic steady state the output multiplier is 0.91 and the welfare multiplier is, by construction, 0 . In a typical recession the output multiplier is slightly higher than 0.91 and it is slightly lower than 0.91 in a typical expansion, suggesting that the output multiplier is countercyclical. Nevertheless, the differences in the output multiplier in the three different states are very small. In contrast, the welfare multiplier is negative in a typical recession and positive in a typical expansion (-0.21 in a typical recession and 0.19 in a typical expansion under a second order approximation). This is suggestive that the welfare multiplier is procyclical and significantly more volatile than the output multiplier. There is little important difference in the values of either the output or welfare multipliers across second or third order approximations.

Table 4 shows some statistics on the output and welfare multipliers from a simulation. For this exercise we simulate 10,000 periods starting from the non-stochastic steady state. At each point in the simulated state space we compute the output and welfare multipliers. For the purposes of generating these statistics the first 100 periods of the simulation are dropped so as to limit the influence of the assumed starting position of the state. We again conduct this exercise for both a second and third order approximation.

We focus first on the results from the second order approximation. The mean output multiplier across simulations is 0.91 , very close its value evaluated in the steady state. The output multiplier is close to constant - its standard deviation is 0.0037 , with a minimum value of 0.89 and a maximum value of 0.93 . The average welfare multiplier is -0.015 , slightly below its steady state value. It is two orders of magnitude more volatile than the output multiplier, with a standard deviation of 0.30 , a minimum value of about -1 , and a maximum of about 1 . The output multiplier is countercyclical - its correlation with the simulated level of output is -0.4. The welfare multiplier, in contrast, is procyclical, with a correlation with output of about 0.4. The two multipliers are negatively correlated with each other (correlation of -0.3), and both multipliers are negatively correlated with the inflation rate, the welfare multiplier more strongly so than the output multiplier.

The results using a third order approximation are qualitatively similar to those from a second order solution. Both multipliers are slightly more volatile under a third order approximation, 
though the differences are not large. The cyclicalities of the multipliers are virtually identical as in the second order approximation. The distribution of both multipliers is slightly skewed to the left under the third order approximation, with the minimum and maximum values of both multipliers smaller relative to the second order approximation. In particular, the skewness coefficients of the output and welfare multipliers in the third order approximation are -0.45 and -0.35 , respectively, whereas the skewness coefficients in the second order approximation are both approximately zero.

Figure 1 plots the simulated values of the output and welfare multiplier over the first 1000 periods of the simulation used to generate the statistics in Table 4. The gray shaded regions are "recessions" defined to be periods when output is in its bottom 20th percentile. Focusing on the axis scaling it is clear that the output multiplier moves very little while the welfare multiplier is quite volatile. During most of the periods identified as recessions the output multiplier is high and tends to rise. In contrast, the welfare multiplier tends to be low in recessions.

Interestingly, the elasticity of output with respect to government spending, $\frac{d \ln Y_{t}}{d \ln G_{t}}$, is quite volatile and countercyclical across states, much more so than the output multiplier, $\frac{d Y_{t}}{d G_{t}}$. Ramey and Zubairy (2014) note that empirical work on state-dependent multipliers often computes elasticities and converts them to multiplier form by post-multiplying by the average ratio of output to government spending. They argue that this approach is likely to overstate the movements in the multiplier across states. This is because $\frac{Y_{t}}{G_{t}}$ is countercyclical, so post-multiplying by the average ratio biases the output multiplier up in a recession and down in an expansion. Our analysis confirms that this criticism is likely to be quantitatively important. In particular, if we were to compute multipliers by converting elasticities using the average output-spending ratio, the output multiplier would range between about 0.8 and 1.1 across states, when in fact the actual multiplier is close to constant.

Even though the medium scale DSGE model is markedly more complicated than the simple NK model, we can nevertheless tie the quantitative results concerning the state-dependence of the output and welfare multipliers back to the intuition developed in Section $2 .{ }^{8}$ Although the model features significant time-varying distortions resulting from monopoly power and price and wage stickiness, the basic intuition from a simple efficient allocation seems to carry over, with the welfare multiplier procylical. Both multipliers are negatively correlated with the inflation rate, consistent with the intuition from the price dispersion terms in (22) and (24). The fact that the output multiplier is close to constant suggests that there is not much loss from using a first order approximation to study the output effects of government spending shocks. The welfare multiplier, in contrast, is quite volatile. The fact that it is procyclical suggests that there is not a strong case to be made for countercyclical government spending in the context of this model.

\footnotetext{
${ }^{8}$ We should be clear that the expressions for the output and welfare multiplier derived in Section 2 would not be identical in this model due to the presence of capital, wage rigidity, habit formation, and variable utilization. One can derive expressions that highlight the same forces in the medium scale model, but they are substantially more complicated and not as straightforward to use for intuition. The Appendix to this paper derives these expressions in the medium scale model.
} 


\subsection{Interest Rate Peg}

In our baseline analysis we assume that monetary policy is conducted via a conventional Taylor rule. Much of the renewed interest in fiscal policy has been driven by the recent period of very low interest rates and the recognition that fiscal policy may be substantially more effective when monetary policy is in a passive regime.

In this section we analyze the effects of passive monetary policy for the state-dependence of the output and welfare multipliers. In particular, we simulate the effects of a passive monetary regime, such as would be the case at the zero lower bound, by assuming that the central bank pegs the nominal interest rate at a fixed value for a number of periods, after which time it reverts to a conventional Taylor rule. Formally, such a policy is characterized by:

$$
i_{t+h}= \begin{cases}i_{t-1} & \text { if } h<H \\ \left(1-\rho_{i}\right) i^{*}+\rho_{i} i_{t+h-1}+\left(1-\rho_{i}\right)\left(\phi_{\pi}\left(\pi_{t+h}-\pi^{*}\right)+\phi_{y}\left(\ln Y_{t+h}-\ln Y_{t+h-1}\right)\right)+s_{i} e_{i, t+h} & \text { if } h \geq H\end{cases}
$$

In this specification $H \geq 0$ is the length of the peg; $H=0$ corresponds to the case of the normal Taylor rule. We assume that the length of the interest rate peg is deterministic and known by all agents. Our results are similar when using a stochastic peg length. For a discussion on the merits of a stochastic versus deterministic peg, see Carlstrom, Fuerst, and Paustian (2014).

For the sake of brevity we focus on peg lengths of four and eight quarters. For these exercises we solve the model using a second order approximation. Since an interest rate peg can be understood as a temporary deviation from normal monetary policy, we do not pick $\varphi$ to set the welfare multiplier to zero when the economy sits in steady state but the interest rate is pegged; rather, $\varphi$ is chosen so that the welfare multiplier equals zero in steady state when policy is conducted according to the estimated Taylor rule. We simulate data from the model characterized by the Taylor rule and at each point in the state space compute the output and welfare multipliers under an interest rate peg. ${ }^{9}$ Table 5 presents statistics from these simulations.

Under both the four and eight quarter peg, the steady state output multiplier is higher than under the conventional Taylor rule. The difference is much more marked for the eight quarter peg, with a steady state output multiplier of 1.20 (as opposed to 0.91 under a Taylor rule and 0.98 under a four quarter peg). ${ }^{10}$ In terms of the intuition from the stripped down version of the model, the higher output multiplier obtains because an increase in government spending has a much bigger effect on real marginal cost when the nominal interest rate is fixed. The higher output multipliers in steady state under an interest rate peg translate into larger steady state welfare

\footnotetext{
${ }^{9}$ This is a subtle but important point worth reemphasizing. The model economy is much more volatile under an interest rate peg than when policy follows the Taylor rule. If we simulated states from the model where policy follows a peg the distribution of states would be much wider, which would tend to inflate the volatility across states in the multipliers. For the exercises in this section we use exactly the same states as we do in our baseline exercises, with the only difference being the deterministic peg on interest rates.

${ }^{10}$ The average values of the multiplier under these different peg lengths are somewhat smaller than what often obtains in versions of the model without capital but are very similar to the estimates from the multiplier at the zero lower bound in the medium scale model of Christiano, Eichenbaum, and Rebelo (2011). In particular they find that the multiplier under a four quarter interest rate peg is similar to the Taylor rule multiplier (about 0.9) and that the multiplier under an eight quarter interest rate peg is about 1.2, just as in our model.
} 
multipliers. Recalling that $\varphi$ is fixed so that the welfare multiplier is zero under a Taylor rule, a larger output multiplier results in a larger welfare multiplier via the "Inefficiency" term in (24) since the economy is distorted on average, a higher output multiplier because of passive monetary policy makes government spending relatively more attractive, other things being equal. For both the output and welfare multipliers, the average multipliers are slightly higher than the steady state multipliers, with the differences between means and steady state substantially larger for the welfare multiplier, particularly under an eight quarter peg.

A key result in Table 5 is that both the output and welfare multipliers are more volatile across states under an interest rate peg than when policy is governed by the Taylor rule. This is evident for the four quarter peg, but is particularly stark for an eight quarter peg. Under an eight quarter peg, the standard deviation of the output multiplier is 0.13 (compared to 0.004 under a Taylor rule), while the volatility of the welfare multiplier is 9.4 (compared to 0.3 under the Taylor rule). The output multiplier ranges from a minimum of 0.7 to a maximum of 1.8. Interestingly, the output multiplier is mildly procyclical (compared to countercyclical under the Taylor rule), though its correlation with the simulated level of output is not large. The welfare multiplier is also mildly procyclical, with a correlation with the simulated level of output of 0.05 . That the welfare multiplier is less procylical than under the Taylor rule makes sense in light of the analytic expression for the welfare multiplier in the simpler NK model - a larger average output multiplier means that the "Inefficiency" term in the welfare multiplier expression is stronger, which counteracts the procyclicality of the welfare multiplier induced by the "Efficiency" term. Nevertheless, the higher output multiplier working through the "Inefficiency" term is not strong enough to flip the correlation of the welfare multiplier with simulated output to negative. Both the output and welfare multipliers are negatively correlated with the simulated level of inflation, more strongly so than under the Taylor rule. This makes sense in light of the price dispersion terms in the analytic expression for the output and welfare multipliers in Section 2 - under an interest rate peg, inflation, and hence price dispersion, increases significantly more after a government spending increase than under a Taylor rule.

The simulation results in Table 5 calculate output and welfare multipliers under an interest rate peg at many different states, most of which feature a positive nominal interest rate far away from zero. One might wonder how, if at all, our results would change if we restricted attention to low interest rate states where the zero lower bound is likely to be binding. Table 6 restricts attention to states where the simulated interest rate is negative, and computes output and welfare multipliers assuming four and eight quarter deterministic interest rate pegs. About nine percent of the simulated states in our baseline analysis feature a negative nominal rate; this frequency would be significantly lower, and more in line with the observed frequency of zero interest rates, if we had assumed positive trend inflation.

The main difference evident between the results in Table 6 (states where the zero lower bound would be binding) and Table 5 (all states) is that both the mean output and welfare multipliers are higher in low interest rate states relative to all states. For example, in a low interest rate state under an eight quarter peg the mean output multiplier is 1.28 and the mean welfare multiplier is 6.42 (compared to mean multipliers of 1.21 and 0.71 in all states). The reason that the mean 
multipliers are both higher in low interest rate states is because inflation is on average low when the interest rate is at zero. When inflation is low, the extra inflation caused by an increase in government spending actually lowers price dispersion; from the analytical approximations for the output and welfare multipliers in Section 2, a negative effect on price dispersion pushes both the output and welfare multipliers up. Aside from the higher mean values of the multipliers, the results from the simulations conditioning on low interest rate states are otherwise similar to the results in Table 5. In particular, the volatilities of both multipliers are similar, as are the correlations of the multipliers with simulated output and inflation.

There are a couple of key take-aways from these exercises under an interest rate peg. First, there is substantially more state-dependence in both the output and welfare multipliers than when policy is governed by a Taylor rule, particularly in the case of an eight quarter peg. This suggests that linear approximations may be inadequate for studying the effects of government spending shocks on output at the zero lower bound, which does not seem to be the case when policy is governed by the Taylor rule. Second, while the welfare multiplier is higher under an interest rate peg than a Taylor rule, it is still positively correlated with the level of output (albeit this correlation is smaller than in our baseline exercises, consistent with the intuition developed in Section 2). While the zero lower bound may be more likely to arise in periods where output is low, and the welfare multiplier is on average much higher during such periods, the large welfare benefits of government spending result not from output being low per se but rather because of the passivity of monetary policy.

\subsection{Government Financing}

In our baseline analysis we assume that all government finance is from lump sum taxes. This facilitates comparison with the literature and in some sense gives government spending shocks their "best chance" to stimulate both output and welfare, but is empirically unrealistic. In this section we consider robustness to different forms of government finance. We revert to assuming that monetary policy is characterized by the estimated Taylor rule.

We consider five different financing regimes, with results shown in Table 7 . The different financing regimes are labeled (i)-(v) and are shown in rows. In all of these specifications the steady state values of the distortionary tax rates are set to $\tau^{n}=0.20, \tau^{c}=0.05$, and $\tau^{k}=0.10$. We fix the steady state government debt to GDP ratio at 0.5 . The steady state value of lump sum taxes is then chosen to make the government budget constraint hold in steady state. In (i) we assume that the distortionary tax rates are fixed at their steady state values, with variable financing coming from lump sum taxes, with $\gamma_{T}=0.1$ and $\rho_{T}=0 .{ }^{11}$ In the remainder of the specifications we assume that lump sum taxes are fixed, with $\gamma_{T}=0$. Specification (ii) assumes that all three tax rates react to deviations of debt from steady state quickly, with $\gamma_{l}=0.1$ and $\rho_{l}=0$ for $l=n, c, k$. In (iii) the coefficients on debt are the same, but tax rates react more gradually to deviations of debt from steady state, with $\rho_{l}=0.9$ for $l=n, c, k$. Specifications (iv) and (v) assume that only the labor

\footnotetext{
${ }^{11}$ If all variable government finance is from lump sum taxes, then the timing of lump sum taxes is irrelevant, and it is therefore without loss of generality to assume that $\rho_{T}=0$.
} 
income tax reacts to debt, with $\gamma_{c}=\gamma_{k}=0$. In (iv) labor income taxes react quickly, with $\gamma_{n}=0.1$ and $\rho_{n}=0$. In (v) the response is more gradual, with $\rho_{n}=0.9$. The table is structured similarly to Table 4, with statistics based on 10,000 periods simulated from the model. For each different specification the value of $\varphi$ is chosen to normalize the welfare multiplier to zero in steady state.

Row (i) of Table 7 considers the case where steady state distortionary taxes are positive but these tax rates are fixed, with all other variable finance coming from lump sum taxes. Unsurprisingly this makes little difference relative to our baseline case. The only small differences are that the welfare multiplier is slightly less volatile and a little more procyclical. Overall, though, the presence of fixed distortionary taxes has very little effect on any of the results.

There are more substantial differences relative to our baseline exercise when lump sum taxes are unavailable and variable finance comes through changes in distortionary tax rates. There are several interesting results to highlight. First, the average output multipliers tend to be lower when distortionary taxes adjust to finance government deficits. This is intuitive since increases in any of the three tax rates have a depressing effect on private spending. Interestingly, the output multipliers are smaller when the increase in taxes is more delayed, as in specifications (iii) and (v). Second, there is substantially more state-dependence in both the output and welfare multipliers when distortionary taxes adjust. In particular, the volatility of the output multiplier is between two and three times as big in these specifications relative to our baseline exercise, and the output multiplier varies by as much as 0.1 across states (relative to about 0.03 in our baseline). The welfare multiplier is also substantially more volatile. Third, the output multiplier is countercyclical and the welfare multiplier is procyclical, just as in our baseline exercises. The presence of distortionary tax finance only serves to strengthen these cyclicalities - in all of these specifications, the output multiplier is more countercyclical, and the welfare multiplier more procyclical, relative to the baseline. The heightened procyclicality of the welfare multiplier is quite intuitive. In all specifications where distortionary tax rates react to finance government expenditure, the output multiplier is smaller relative to the case where lump sum taxes are used. The smaller output multiplier makes the "Inefficiency" term in the welfare multiplier expression weaker, thereby resulting in a more procyclical welfare multiplier.

\subsection{Parameters}

We also consider the robustness of our results to a few select parameters. Results are shown in Table 8. Rows indicate parameters whose values are different than our baseline exercise. All other nonlisted parameters are fixed at their baseline calibrated or estimated values. Government finance is through lump sum taxes and monetary policy follows the estimated Taylor rule. In all specifications the parameter $\varphi$ is chosen so that the welfare multiplier equals zero evaluated in steady state. The model is solved via a second order approximation. All numbers in the Table represent statistics generated via a 10,000 period simulation of the model, discarding the first 100 observations.

The first row considers the case where prices and wages are both flexible, i.e. $\theta_{p}=\theta_{w}=0$. This

results in a lower steady state value of the output multiplier than in our baseline exercise $(0.88$ 
here vs. 0.91 in the baseline). The lower value of the output multiplier is to be expected based on the intuition from the analytic expression for the output multiplier in Section 2. When prices and wages are flexible, real marginal cost is fixed, which unambiguously results in a lower output multiplier. Interestingly, the output multiplier is about twice as volatile with flexible prices and wages relative to the baseline case, and is also slightly more countercyclical, though it still varies little across states in an absolute sense. The welfare multiplier is about as volatile with flexible prices and wages as in the baseline case. It is more procyclical here, however. This makes sense in light of the analytic expression for the welfare multiplier. When prices and wages are flexible, the overall level of distortion in the economy is not time-varying, which weakens the effect of the "Inefficiency" term in the analytic expression for the welfare multiplier.

The next row considers the case in which there is no variable capital utilization, which occurs when the parameter $\delta_{2} \rightarrow \infty$ (in practice we set this parameter equal to 1000). Given that variable utilization is a significant source of amplification, it is unsurprising that the output multiplier is lower in this specification than in our baseline (steady state multiplier of 0.86 as opposed 0.91). It is, however, slightly more volatile across states than in our baseline exercise, but is a little less countercyclical. The output multiplier is nevertheless still close to constant. The welfare multiplier is also slightly more volatile with no variable utilization, and is again procyclical, with a correlation with simulated output of 0.64 . This correlation is substantially higher than in our baseline. The intuition for this higher correlation with output is that the lower output multiplier weakens the "Inefficiency" term in the analytic expression for the welfare multiplier derived in Section 2.

The middle row in the table, labeled $\chi=0.5$, considers the case when labor supply is more elastic (the Frisch labor supply elasticity is the inverse of $\chi$ ). This has the effect of increasing the output multiplier relative to our benchmark case (0.94 instead of 0.91 evaluated in steady state). The volatility of the output multiplier is slightly lower than in our baseline, though the output multiplier is again approximately constant. The welfare multiplier is roughly as volatile as in our baseline analysis, and remains procyclical.

The next row, labeled $\rho_{g}=0.8$, considers the case when government spending shocks are less persistent than in the baseline. This results in a higher value of the mean output multiplier $(0.95$, compared to about 0.91 in the baseline). When government spending shocks are less persistent, the negative wealth effect on consumption is smaller, and so there is less crowding out of private expenditure, resulting in a larger multiplier. With a lower value of $\rho_{g}$ both the output and welfare multipliers are substantially less volatile than in our baseline exercise. The output multiplier is about as countercyclical, but the welfare multiplier is much less procyclical. The smaller degree of procyclicality in the welfare multiplier is to be expected because of the higher output multiplier in conjunction with the "Inefficiency" term in the analytic approximation for the welfare multiplier from Section 2. Nevertheless, the welfare multiplier remains mildly procyclical, with a correlation coefficient with simulated output of about 0.10 .

The final row in Table 8 considers a more aggressive monetary policy, with reaction coefficient on inflation of $\phi_{\pi}=4$ (instead of 2.1, as in our baseline). The results from the simulation are in a sense the mirror image of what happens under an interest rate peg, albeit on a much smaller 
scale. The more active monetary policy rule results in a slightly lower average output multiplier. The volatilities of the output and welfare multipliers are about the same as in our baseline exercise. The output multiplier is mildly countercyclical and the welfare multiplier is procyclical, and the procyclicality of the welfare multiplier is slightly stronger here than in the baseline exercise (correlation with simulated output of 0.48 as opposed to 0.37 in the baseline).

We also consider the effects of different shocks in driving our results. For these exercises we generate states conditioning on particular shocks. For example, consider the neutral productivity shock. We set the variances of the investment, labor supply, intertemporal preference, and monetary shocks to zero, keep the variance of the government spending shock at its estimated value, and solve for the standard deviation of the productivity shock to generate the same volatility of the level of output as in the baseline estimated model. All other parameters are held fixed at their calibrated or estimated values, all government finance is lump sum, and monetary policy is characterized by a Taylor rule. We then generate 10,000 periods of artificial data from the model with the altered shock variances, and compute the output and welfare multipliers at each point in the simulated state space. We do this for each of the five shocks other than government spending. Results are summarized in Table 9.

In terms of movements across states there is not much difference conditional on different shocks for either multiplier. The output multiplier is close to constant and the welfare multiplier is quite volatile. Though the differences relative to our baseline analysis are small, the output multiplier differs most across states conditional on the investment and intertemporal preference shocks (standard deviations of 0.0052 and 0.0065 , compared to 0.0037 in the baseline), while the welfare multiplier is most volatile conditional on the intertemporal preference shock (standard deviation of 0.4049, compared to 0.3044 in the baseline). The output multiplier is countercyclical conditional on all shocks, though it is most negatively correlated with simulated output conditional on the productivity shock. The welfare multiplier is negatively correlated with inflation conditional on all shocks.

The most interesting difference evident in Table 9 relative to our baseline analysis is the cyclicality of the welfare multiplier conditional on different shocks. The welfare multiplier is most strongly procyclical conditional on the productivity and labor supply shocks, is mildly procyclical conditional on the investment shock, and is countercyclical conditional on the preference and monetary shocks. This finding accords with the intuition from the simpler version of the model discussed in Section 2 that the welfare multiplier ought to be most procyclical conditional on "supply shocks" and less procylical conditional on "demand shocks" (the investment, intertemporal preference, and monetary shocks are "demand shocks" in that they are associated with output and inflation moving in the same direction). The reason that we estimate the welfare multiplier to be procyclical with all shocks is that the preference and monetary shocks are not estimated to be particularly important driving forces for output. The most important shock for the dynamics of output is the investment shock, and while this does move output and inflation in the same direction, the welfare multiplier is still mildly procyclical conditional on this shock. While countercyclical government spending is not desirable in the model in an average sense, these results nevertheless do suggest that there may 
be particular episodes when output is low due to adverse demand conditions where countercyclical government spending may be beneficial from the perspective of social welfare.

\section{Conclusion}

The objective of this paper has been to study how the output and welfare effects of changes in government spending vary over the business cycle in a canonical medium scale DSGE model. The output multiplier is countercyclical but moves very little across states when monetary policy is characterized by a Taylor rule. There is substantially more state-dependence in the output multiplier under an interest rate peg. The welfare multiplier is robustly procyclical. This result casts doubt on the desirability of countercyclical government spending as a general policy proscription.

We conclude by reiterating the caveat that our results are dependent on the structure of the model. We have not sought to write down a model to deliver particular results, but rather to study the question of how the output and welfare effects of changes in government spending vary across states in a version of a popular model in wide use by academics and central bankers. A different model may yield different results, and we plan to pursue several extensions in future research. 


\section{References}

Auerbach, Alan and Yuriy Gorodnichenko. 2012. "Measuring the Output Responses to Fiscal Policy." American Economic Journal: Economic Policy 4(2), 1-27.

Bachmann, Rüdiger, and Eric R. Sims. 2012. "Confidence and the Transmission of Government Spending Shocks." Journal of Monetary Economics 59(3), 235-249.

Barro, Robert J. 1981. "Output Effects of Government Purchases." Journal of Political Economy 89(6): 1086-1021.

Barro, Robert J., and Charles J. Redlick. 2011. "Macroeconomic Effects from Government Purchases and Taxes." The Quarterly Journal of Economics 126(1), 51-102.

Baxter, Marianne and Robert G. King. 1993. "Fiscal Policy in General Equilibrium." American Economic Review 83(3), 315-334.

Blanchard, Oliver, and Roberto Perotti. 2002. "An Empirical Characterization of the Dynamic Effects of Changes in Government Spending and Taxes on Output." The Quarterly Journal of Economics 117(4), 1329-1368.

Braun, R. Anton, Lena Mareen Koerber, and Yuichiro Waki. 2012. "Some Unpleasant Properties of Log-Linearized Solutions When the Nominal Rate is Zero." Federal Reserve Bank of Atlanta Working Paper 2012-5a.

Carlstrom, Charles, Timothy Fuerst, and Matthias Paustian. 2014. "Fiscal Multipliers Under an Interest Rate Peg of Deterministic versus Stochastic Duration." Journal of Money, Credit, and Banking 46(6): 1293-1312.

Chari, VV, Patrick J. Kehoe, and Ellen R. McGrattan. 2007. "Business Cycle Accounting." Econometrica 75(3), 781-836.

Christiano, Lawrence J. 2004. "The Zero Bound, Zero-Inflation Targeting, and Output Collapse." Working paper, Northwestern University.

Christiano, Lawrence J., Martin Eichenbaum, and Charles L. Evans. 2005. "Nominal Rigidities and the Dynamic Effects of a Shock to Monetary Policy." Journal of Political Economy $113(1), 1-45$.

Christiano, Lawrence J., Martin Eichenbaum, and Sergio Rebelo. 2011. "When is the Government Spending Multiplier Large?" Journal of Political Economy 119(1), 78-121.

Coenen, Günter, Christopher Erceg, Charles Freedman, Davide Furceri, Michael Kumhof, René Lalonde, Douglas Laxton, Jesper Lendé, Annabelle Mourougane, Dirk Muir, Susanna Mursula, Carlos de Resende, John Roberts, Werner Roeger, Stephen Snudden, Mathias Trabandt, and Jan in't Veld. 2012. "Effects of Fiscal Stimulus in Structural Models" American Economic Journal: Macroeconomics 4(1), 22-68.

Cogan, John F., Tobias Cwik, John B. Taylor, and Volker Wieland. 2010. "New Keynesian Versus Old Keynesian Government Spending Multipliers." Journal of Economic Dynamics 
and Control 34(3), 281-295.

Drautzburg, Thorsten and Harald Uhlig. 2011. "Fiscal Stimulus and Distortionary Taxation." ZEW-Centre for European Economic Research Discussion Paper No. 11-03\%.

Eichenbaum, Martin and Jonas Fisher. 2005. "Fiscal Policy in the Aftermath of 9/11." Journal of Money, Credit, and Banking 37(1), 1-22.

Eggertsson, Gauti B. and Michael Woodford. 2003. " The Zero Bound on Interest Rates and Optimal Monetary Policy." Brookings Papers on Economic Activity 1: 212-219.

Eggertsson, Gauti B. 2011. "What Fiscal Policy is Effective at Zero Interest Rates?" NBER Macroeconomic Annual 2010, University of Chicago Press, 2011.

Erceg, Christopher, Dale Henderson, and Andrew Levin. 2000. "Optimal Monetary Policy with Staggered Wage and Price Contracts." Journal of Monetary Economics 46(2): 281-313.

Hall, Robert E. 1986. "The Role of Consumption in Economic Fluctuations" in Robert J. Gordon, ed., The American Business Cycle: Continuity and Change, University of Chicago Press for the National Bureau of Economic Research, pp. 237-255.

Hall, Robert E. 2009 "By How Much Does GDP Rise if the Government Buys More Uutput?" NBER Working Paper 15496.

Justiniano, Alejandro, Giorgio Primiceri, and Andrea Tambalotti. 2010. "Investment Shocks and Business Cycles." Journal of Monetary Economics 57(2), 132-145.

Krugman, Paul. 1998. "It's Baaack: Japan's Slump and the Return of the Liquidity Trap." Brookings Papers on Economic Activity 2: 137-187.

Leeper, Eric M., Nora Traum, and Todd B. Walker. 2011. "Clearing up the Fiscal Multiplier Morass." NBER Working Paper 2011.

Mittnik, Stefan and Willi Semmler. 2012. "Regime Dependence of the Fiscal Multiplier." Journal of Economic Behavior and Organization 83, 502-522.

Mounford, Andrew, and Harald Uhlig. 2009. "What are the Effects of Fiscal Policy Shocks?" Journal of Applied Econometrics 24(6), 960-992.

Nakamura, Emi and Jon Steinsson. 2014. "Fiscal Stimulus in a Monetary Union: Evidence from US Regions." American Economic Review 104(3), 753-792.

Nakata, Taisuke. 2013. "Optimal Fiscal and Monetary Policy with Occasionally Binding Zero Bound Constraints." Working Paper.

Parker, Jonathan. 2011. "On Measuring the Effects of Fiscal Policy in Recessions." Journal of Economic Literature 49(3), 703-718.

Ramey, Valerie A., and Matthew D. Shapiro. 1998. "Costly Capital Reallocation and the Effects of Government Spending." Carnegie-Rochester Conference Series on Public Policy 48: 145194. 
Ramey, Valerie A. 2011. "Identifying Government Spending Shocks: It's all in the Timing." The Quarterly Journal of Economics 126(1), 1-50.

Ramey, Valerie A. and Sarah Zubairy. 2014. "Government Spending Multipliers in Good Times and in Bad: Evidence from US Historical Data." NBER Working Paper 20719.

Shoag, Daniel. 2015. "The Impact of Government Spending Shocks: Evidence on the Multiplier from State Pension Plan Returns." Working paper, Harvard University.

Smets, Frank and Raf Waters. 2007. "Shocks and Frictions in US Business Cycles: A Bayesian DSGE Approach." American Economic Review 97(3), 586-606.

Woodford, Michael. 2011. "Simple Analytics of the Government Expenditure Multiplier." American Economics Journal: Macroeconomics 3(1), 1-35

Zubairy, Sarah. 2014. "On Fiscal Multipliers: Estimates from a Medium Scale DSGE Model." International Economic Review 55(1): 169-195. 


\section{Table 1: Calibrated Parameters}

\begin{tabular}{cc}
\hline \hline Parameter & Value \\
\hline$\beta$ & 0.995 \\
$\alpha$ & $1 / 3$ \\
$\delta_{0}$ & 0.025 \\
$\delta_{1}$ & Normalize $u^{*}=1$ \\
$\delta_{2}$ & 0.01 \\
$\epsilon_{p}$ & 11 \\
$\epsilon_{w}$ & 11 \\
$\psi$ & 6 \\
$F$ & Normalize $\Pi^{*}=0$ \\
$G^{*}$ & 0 \\
$\pi^{*}$ & 0 \\
$\tau^{c}, \tau^{k}, \tau^{n}$ & 0 \\
$\gamma_{c}, \gamma_{k}, \gamma_{n}$ & 0 \\
$\rho_{c}, \rho_{k}, \rho_{n}$ & Steady State $\frac{G^{*}}{Y^{*}}=0.2$ \\
\hline \hline
\end{tabular}

Note: This table shows the values of calibrated parameters. The rational for these values is described in the text. As a benchmark, we assume that all government finance is lump sum; as such, we set the parameters of the distortionary tax processes (including the steady state values) all to zero. Because the timing of lump sum finance is irrelevant, we assume that $T_{t}=G_{t}$, and therefore do not need to specify values of steady state government debt or the parameters governing the process for lump sum taxes. 
Table 2: Estimated Parameters

\begin{tabular}{|c|c|c|c|c|c|c|}
\hline \multirow[b]{2}{*}{ Parameter } & \multirow[b]{2}{*}{ Dist. } & \multicolumn{2}{|c|}{ Prior } & \multicolumn{3}{|c|}{ Posterior } \\
\hline & & Mean & $\mathrm{SD}$ & Mode & Mean & $\mathrm{SD}$ \\
\hline$b$ & Beta & 0.50 & 0.20 & 0.82 & 0.82 & 0.0571 \\
\hline$\chi$ & Gamma & 1.00 & 0.50 & 1.08 & 1.07 & 0.0474 \\
\hline$\kappa$ & Gamma & 4.00 & 1.00 & 5.24 & 5.77 & 0.9897 \\
\hline$\theta_{w}$ & Beta & 0.66 & 0.10 & 0.50 & 0.52 & 0.0861 \\
\hline$\theta_{p}$ & Beta & 0.66 & 0.10 & 0.70 & 0.69 & 0.0373 \\
\hline$\zeta_{w}$ & Beta & 0.50 & 0.20 & 0.28 & 0.37 & 0.2027 \\
\hline$\zeta_{p}$ & Beta & 0.50 & 0.20 & 0.04 & 0.07 & 0.0323 \\
\hline$\phi_{\pi}$ & Normal & 1.70 & 0.30 & 2.09 & 2.08 & 0.1904 \\
\hline$\phi_{y}$ & Normal & 0.12 & 0.05 & 0.18 & 0.18 & 0.0430 \\
\hline$\rho_{i}$ & Beta & 0.60 & 0.10 & 0.81 & 0.81 & 0.0195 \\
\hline$\rho_{a}$ & Beta & 0.60 & 0.10 & 0.90 & 0.89 & 0.0217 \\
\hline$\rho_{z}$ & Beta & 0.60 & 0.10 & 0.68 & 0.65 & 0.0672 \\
\hline$\rho_{\nu}$ & Beta & 0.60 & 0.10 & 0.64 & 0.62 & 0.1255 \\
\hline$\rho_{\xi}$ & Beta & 0.60 & 0.10 & 0.80 & 0.76 & 0.0639 \\
\hline$\rho_{g}$ & Beta & 0.60 & 0.10 & 0.94 & 0.94 & 0.0129 \\
\hline$s_{i}$ & Inv. Gamma & 0.001 & 0.010 & 0.0013 & 0.0013 & 0.0001 \\
\hline$s_{a}$ & Inv. Gamma & 0.005 & 0.010 & 0.0048 & 0.0049 & 0.0004 \\
\hline$s_{z}$ & Inv. Gamma & 0.005 & 0.010 & 0.0480 & 0.0554 & 0.0106 \\
\hline$s_{\nu}$ & Inv. Gamma & 0.001 & 0.010 & 0.0237 & 0.0264 & 0.0067 \\
\hline$s_{\xi}$ & Inv. Gamma & 0.001 & 0.001 & 0.0758 & 0.0996 & 0.0320 \\
\hline$s_{g}$ & Inv. Gamma & 0.001 & 0.010 & 0.0083 & 0.0084 & 0.0006 \\
\hline
\end{tabular}

Note: The log-posterior density at the mode is 2563.16. The variables used in the estimation are the growth rates of output, consumption, and labor hours, and the levels of the interest rate, the inflation rate, and the government spending to output ratio. The construction of these series is described in the text. The sample period for the estimation is $1984 \mathrm{q} 1-2008 \mathrm{q} 3$. 


\section{Table 3: Output and Welfare Multipliers Across the State Space}

\begin{tabular}{|c|c|c|c|}
\hline & Steady State & Recession & Expansion \\
\hline \multicolumn{4}{|l|}{ 2nd Order } \\
\hline Output Multiplier & 0.9099 & 0.9135 & 0.9079 \\
\hline Welfare Multiplier & 0.0000 & -0.2106 & 0.1857 \\
\hline \multicolumn{4}{|l|}{ 3rd Order } \\
\hline Output Multiplier & 0.9099 & 0.9124 & 0.9065 \\
\hline Welfare Multiplier & 0.0000 & -0.1847 & 0.1944 \\
\hline \multicolumn{4}{|c|}{$\begin{array}{l}\text { Note: This table shows output and welfare multipliers in three different states: the } \\
\text { non-stochastic steady state, the average state in a recession, and the average state } \\
\text { in an expansion. The numbers outside of steady state are generated from simulating } \\
10,000 \text { periods (starting from the non-stochastic steady state). We define "recession" } \\
\text { and "expansion" to mean the lower and upper } 20 \text { th percentile of simulated output, av- } \\
\text { erage the simulated state vector in recessions and expansions so defined, and compute } \\
\text { output and welfare multipliers starting from those averaged state vectors. The panel } \\
\text { labeled "2nd Order" solves and simulates the model via a second order approximation, } \\
\text { while the panel labeled "3rd Order" solves and simulates the model via a third order } \\
\text { approximation. The parameter } \varphi \text { is chosen so as to normalize the welfare multiplier } \\
\text { to be zero evaluated in the non-stochastic steady state. }\end{array}$} \\
\hline
\end{tabular}

Table 4: Output and Welfare Multipliers from Simulations

\begin{tabular}{ccccccc}
\hline \hline & Min & Max & Mean & Std & Corr w/ Output & Corr w/ Inflation \\
\hline 2nd Order & & & & & & -0.4412 \\
Output Multiplier & 0.8949 & 0.9270 & 0.9102 & 0.0037 & 0.3747 & -0.1591 \\
Welfare Multiplier & -1.0300 & 1.0357 & -0.0149 & 0.3044 & & -0.5401 \\
\hline 3rd Order & & & & & -0.4357 & -0.1989 \\
Output Multiplier & 0.8895 & 0.9213 & 0.9085 & 0.0040 & 0.3527 & -0.4982 \\
Welfare Multiplier & -1.3984 & 0.8425 & -0.0123 & 0.3159 & \\
\hline \hline
\end{tabular}

Note: The numbers in this table are moments based on simulating the model at the estimated parameter values for 10,000 periods starting from the non-stochastic steady state. At each point in the simulated states space, we compute output and welfare multipliers. The first 100 periods of the simulation are dropped so as to limit the influence of the assumed starting position. The column labeled "2nd Order" solves and simulates the model via a second order approximation, while the column labeled "3rd Order" does so via a third order approximation. 


\section{Table 5: Output and Welfare Multipliers from Simulations Interest Rate Peg}

\begin{tabular}{ccccccc}
\hline \hline & Min & Max & Mean & Std & Corr w/ Output & Corr w/ Inflation \\
\hline 4 Quarter Peg & & & & & & \\
Output Multiplier & 0.9623 & 0.9932 & 0.9772 & 0.0040 & 0.2302 & -0.7278 \\
Welfare Multiplier & -2.3291 & 2.7157 & 0.1547 & 0.6257 & 0.1676 & -0.8197 \\
\hline 8 Quarter Peg & & & & & & -0.6637 \\
Output Multiplier & 0.6935 & 1.7801 & 1.2053 & 0.1317 & 0.1754 & -0.7312 \\
Welfare Multiplier & -36.8072 & 40.7726 & 1.0389 & 9.4459 & 0.0522 & \\
\hline \hline
\end{tabular}

Note: This table shows multiplier statistics for interest rate pegs of four and eight quarters, respectively. The parameter $\varphi$ is chosen so that the welfare multiplier is zero in steady state under a Taylor rule, not under the interest rate peg. The table is structured similarly to Table 4. The numbers in this table are moments based on simulating the model under the standard Taylor rule at the estimated parameter values for 10,000 periods starting from the non-stochastic steady state. At each point in the simulated state space, we compute output and welfare multipliers where monetary policy is characterized by an interest rate peg for the specified number of quarters. To be specific, we assume that the interest rate is fixed at its previous period's value for either 4 or 8 quarters, after which time monetary policy reverts to the Taylor rule. The first 100 periods of the simulation are dropped so as to limit the influence of the assumed starting position. These numbers are all generated from a second order approximation. The steady state output multipliers are 0.9770 and 1.2018 for the four and eight quarter pegs, respectively. For the welfare multiplier the steady state multipliers are 0.1326 and 0.7053 , respectively.

\section{Table 6: Output and Welfare Multipliers from Simulations Interest Rate Peg, Binding ZLB}

\begin{tabular}{ccccccc}
\hline \hline & Min & Max & Mean & Std & Corr w/ Output & Corr w/ Inflation \\
\hline 4 Quarter Peg & & & & & & \\
Output Multiplier & 0.9682 & 0.9932 & 0.9796 & 0.0041 & 0.2231 & -0.7193 \\
Welfare Multiplier & -1.1661 & 2.1015 & 0.6309 & 0.5659 & 0.1736 & -0.7783 \\
\hline 8 Quarter Peg & & & & & & -0.6409 \\
Output Multiplier & 0.8910 & 1.7801 & 1.2752 & 0.1295 & 0.1469 & -0.7087 \\
Welfare Multiplier & -21.6945 & 40.7726 & 6.4192 & 9.0931 & 0.0301 & \\
\hline \hline
\end{tabular}

Note: This table shows multiplier statistics for interest rate pegs of four and eight quarters, respectively. The parameter $\varphi$ is chosen so that the welfare multiplier is zero in steady state under a Taylor rule, not under the interest rate peg. The numbers in this table are moments based on simulating the model under the standard Taylor rule at the estimated parameter values for 10,000 periods starting from the non-stochastic steady state. We restrict attention to states where the simulated nominal interest rate is negative. At each point in the restricted simulated state space, we compute output and welfare multipliers where monetary policy is characterized by an interest rate peg for the specified number of quarters. To be specific, we assume that the interest rate is fixed at its previous period's value for either 4 or 8 quarters, after which time monetary policy reverts to the Taylor rule. These numbers are all generated from a second order approximation. 


\section{Table 7: Output and Welfare Multipliers from Simulations Different Financing Regimes}

\begin{tabular}{|c|c|c|c|c|c|c|}
\hline & Min & $\operatorname{Max}$ & Mean & Std & Corr w/ Output & Corr w/ Inflation \\
\hline \multicolumn{7}{|l|}{ Financing Regime (i) } \\
\hline Output Multiplier & 0.8971 & 0.9276 & 0.9115 & 0.0036 & -0.4743 & -0.1429 \\
\hline Welfare Multiplier & -0.9333 & 0.9395 & -0.0130 & 0.2728 & 0.4381 & -0.5387 \\
\hline \multicolumn{7}{|l|}{ Financing Regime (ii) } \\
\hline Output Multiplier & 0.8045 & 0.8700 & 0.8345 & 0.0076 & -0.5506 & -0.2068 \\
\hline Welfare Multiplier & -1.5060 & 1.4303 & -0.0419 & 0.4559 & 0.6119 & -0.4836 \\
\hline \multicolumn{7}{|l|}{ Financing Regime (iii) } \\
\hline Output Multiplier & 0.7111 & 0.8134 & 0.7597 & 0.0122 & -0.5876 & -0.2034 \\
\hline Welfare Multiplier & -1.4588 & 1.3926 & -0.0273 & 0.4285 & 0.5054 & -0.5251 \\
\hline \multicolumn{7}{|l|}{ Financing Regime (iv) } \\
\hline Output Multiplier & 0.8565 & 0.8942 & 0.8739 & 0.0045 & -0.5017 & -0.0908 \\
\hline Welfare Multiplier & -1.5668 & 1.4060 & -0.0464 & 0.4644 & 0.6252 & -0.4459 \\
\hline \multicolumn{7}{|l|}{ Financing Regime (v) } \\
\hline Output Multiplier & 0.7226 & 0.8234 & 0.7715 & 0.0119 & -0.4856 & -0.1026 \\
\hline Welfare Multiplier & -1.7599 & 1.6704 & -0.0156 & 0.5256 & 0.5446 & -0.4661 \\
\hline
\end{tabular}

Note: Rows labeled "Financing Regime" (i)-(v) correspond to different fiscal financing regimes. In all rows steady state distortionary taxes are set to $\tau^{n}=0.20, \tau^{k}=0.10$, and $\tau^{c}=0.05$ and the steady state government debt to output ratio is fixed at 0.5 . Row (i) considers the case where steady state distortionary taxes are positive but fixed, with all other variable finance coming from lump sum taxes, with $\gamma_{T}=0.1$. The rest of the rows assume lump sum taxes are fixed, with $\gamma_{T}=0$. Row (ii) has all three distortionary taxes reacting to deviations of debt from target, with $\gamma_{l}=0.1$ for $l=n, c, k$ and $\rho_{l}=0$ for $l=n, c, k$. Row (iii) is similar to (ii), but assumes that tax rates react to debt with a lag, with $\rho_{l}=0.9$ for $l=n, c, k$. In rows (iv) and (v) we assume that variable tax finance comes from labor income taxes alone. Row (iv) assumes that $\gamma_{n}=0.1$ and $\rho_{n}=0$, with $\gamma_{c}=\gamma_{k}=0$. Row (v) is the same but instead assumes $\rho_{n}=0.9$. The table is otherwise structured similarly to Table 4. For each different specification the parameter $\varphi$ is chosen to normalize the welfare multiplier to zero in steady state. The numbers in this table are moments based on simulating the model at the estimated parameter values for 10,000 periods starting from the non-stochastic steady state. At each point in the simulated states space, we compute output and welfare multipliers. The first 100 periods of the simulation are dropped so as to limit the influence of the assumed starting position. These numbers are all generated from a second order approximation. The steady state output multipliers are $0.9112,0.8335,0.7583,0.8736$, and 0.7703 for financing regimes (i)-(v). 


\section{Table 8: Output and Welfare Multipliers from Simulations Parameter Robustness}

\begin{tabular}{|c|c|c|c|c|c|c|}
\hline & Min & $\operatorname{Max}$ & Mean & Std & Corr w/ Output & Corr w/ Inflation \\
\hline \multicolumn{7}{|l|}{$\theta_{p}=\theta_{w}=0$} \\
\hline Output Multiplier & 0.8534 & 0.9103 & 0.8755 & 0.0064 & -0.5198 & -0.3975 \\
\hline Welfare Multiplier & -0.9784 & 1.0446 & 0.0096 & 0.3109 & 0.5679 & -0.2322 \\
\hline \multicolumn{7}{|l|}{$\delta_{2}=1000$} \\
\hline Output Multiplier & 0.8426 & 0.8825 & 0.8629 & 0.0047 & -0.3221 & 0.2013 \\
\hline Welfare Multiplier & -1.3832 & 1.4344 & -0.0323 & 0.4009 & 0.6416 & -0.5563 \\
\hline \multicolumn{7}{|l|}{$\chi=0.5$} \\
\hline Output Multiplier & 0.9253 & 0.9511 & 0.9371 & 0.0031 & -0.5968 & -0.1412 \\
\hline Welfare Multiplier & -1.0318 & 1.0955 & -0.0161 & 0.3166 & 0.5056 & -0.5857 \\
\hline \multicolumn{7}{|l|}{$\rho_{g}=0.8$} \\
\hline Output Multiplier & 0.9448 & 0.9639 & 0.9545 & 0.0023 & -0.3473 & -0.2099 \\
\hline Welfare Multiplier & -0.7060 & 0.5669 & -0.0078 & 0.1807 & 0.1032 & -0.7450 \\
\hline \multicolumn{7}{|l|}{$\phi_{\pi}=4$} \\
\hline Output Multiplier & 0.8820 & 0.9219 & 0.8995 & 0.0045 & -0.4180 & -0.3825 \\
\hline Welfare Multiplier & -0.9590 & 1.0116 & -0.0100 & 0.2949 & 0.4760 & -0.4917 \\
\hline
\end{tabular}

Note: The rows in this table correspond to different values of selected parameters. All parameters other than those listed in each row are fixed at their baseline values from Table 1 and Table 2. In each specification the parameter $\varphi$ is chosen so as to normalize the value of the welfare multiplier to zero in steady state. The table is otherwise structured similarly to Table 4 , and the exercises underlying the numbers is identical to our baseline exercise. The steady state output multiplier is 0.8756 when $\theta_{w}=\theta_{p}=0,0.8626$ when $\delta_{2}=1000,0.9368$ when $\chi=0.5,0.9544$ when $\rho_{G}=0.8$, and 0.8922 when $\phi_{\pi}=4$. 


\section{Table 9: Output and Welfare Multipliers from Simulations Conditioning on Shocks}

\begin{tabular}{|c|c|c|c|c|c|c|}
\hline & Min & $\operatorname{Max}$ & Mean & Std & Corr w/ Output & Corr w/ Inflation \\
\hline \multicolumn{7}{|l|}{ Productivity shock } \\
\hline Output Multiplier & 0.9003 & 0.9197 & 0.9102 & 0.0027 & -0.7763 & -0.2778 \\
\hline Welfare Multiplier & -1.1087 & 1.0670 & -0.0188 & 0.2983 & 0.7217 & -0.4325 \\
\hline \multicolumn{7}{|l|}{ Labor supply shock } \\
\hline Output Multiplier & 0.9025 & 0.9195 & 0.9104 & 0.0024 & -0.6916 & 0.2749 \\
\hline Welfare Multiplier & -1.2431 & 1.0598 & -0.0296 & 0.3159 & 0.4523 & -0.7406 \\
\hline \multicolumn{7}{|l|}{ Investment shock } \\
\hline Output Multiplier & 0.8894 & 0.9296 & 0.9099 & 0.0052 & -0.2960 & -0.1485 \\
\hline Welfare Multiplier & -0.7206 & 0.9296 & 0.0531 & 0.2817 & 0.1159 & -0.0683 \\
\hline \multicolumn{7}{|l|}{ Preference shock } \\
\hline Output Multiplier & 0.8883 & 0.9380 & 0.9108 & 0.0065 & -0.5573 & -0.6444 \\
\hline Welfare Multiplier & -1.8184 & 1.0544 & -0.0447 & 0.4049 & -0.1048 & -0.1302 \\
\hline \multicolumn{7}{|l|}{ Monetary shock } \\
\hline Output Multiplier & 0.8955 & 0.9297 & 0.9127 & 0.0045 & -0.0537 & 0.5174 \\
\hline Welfare Multiplier & -1.6168 & 0.5135 & -0.1669 & 0.2542 & -0.4343 & -0.6160 \\
\hline
\end{tabular}

Note: In the different rows we condition on particular shocks in generating states from which to compute multipliers. In particular, in each row we set the variances of all but the listed shock and the government spending shock to zero, and solve for the magnitude of the listed shock to generate the same volatility of the level of output as in the baseline estimated model. We then generate 10,000 periods of simulated data from the model driven by just the listed shock and the government spending shock, and compute the output and welfare multipliers at each point in the simulated state space. All parameters other than the shock variances are fixed at their baseline values from Table 1 and Table 2. In generating these statistics the first 100 periods from each simulation are dropped. The models are solved via a second order approximation. 
Figure 1: Simulated Output and Welfare Multipliers
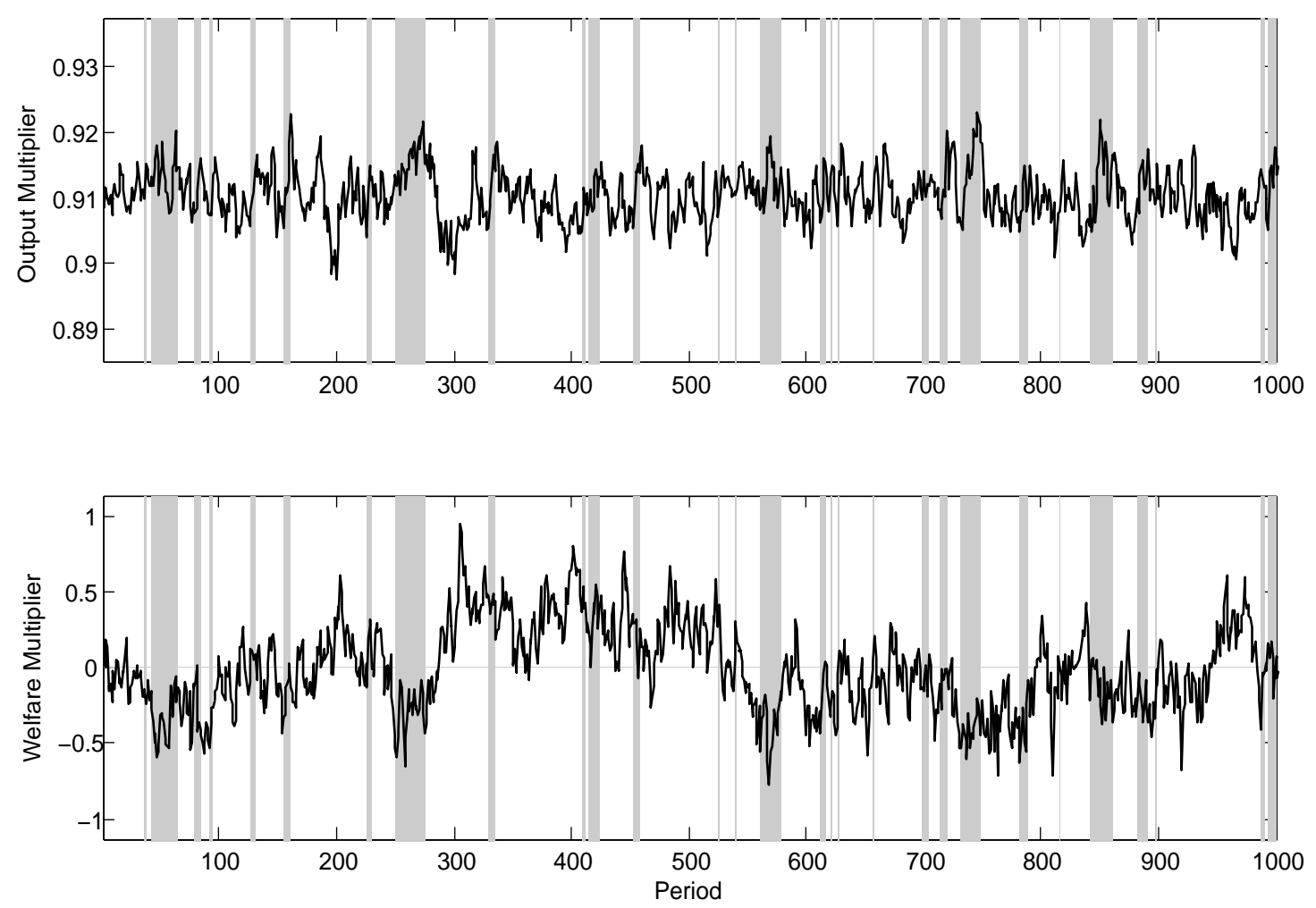

Note: This figure plots simulated time series for the output multiplier (upper panel) and welfare multiplier (lower panel). These simulations are conducted using the estimated parameter values starting from the non-stochastic steady state. Vertical grayshaded areas denote periods when the level of output is in its lowest 20th percentile, meant to proxy for periods of recession. A second order solution method is used to generate the multipliers in this figure. 


\section{A Appendix}

This Appendix provides a detailed derivation of the expressions for the output and utility multipliers presented in the text, equation (22) and (24), respectively. We start with the output multiplier. Combining household optimality conditions (1) and (2) with firm optimality condition (8) yields:

$$
-U_{N}=U_{C} m c_{t} A_{t}
$$

Here it is understood that $F_{X}$ is the partial derivative of a function $F$ with respect to $X$ evaluated at some point. Totally differentiating about a point (denoted by the lack of a time subscript), we have:

$$
-U_{N N} d N_{t}=U_{C C} m c A d C_{t}+U_{C} A d m c_{t}
$$

Here we have made use of the assumption of separability in utility and have held $A_{t}$ fixed at some value $A$ (since it is exogenous and unaffected by changes in government spending). Totally differentiating the expression for the aggregate production function, (17), yields:

$$
d N_{t}=\frac{v^{p}}{A} d Y_{t}+N \frac{d v_{t}^{p}}{v^{p}}
$$

Totally differentiating the aggregate resource constraint, (16) yields:

$$
d C_{t}=d Y_{t}-d G_{t}
$$

Combining (A.3) and (A.4) with (A.2), we have:

$$
-U_{N N}\left[\frac{v^{p}}{A} d Y_{t}+N \frac{d v_{t}^{p}}{v^{p}}\right]=U_{C C} m c A\left[d Y_{t}-d G_{t}\right]+U_{C} A d m c_{t}
$$

Dividing by $d G_{t}$ and simplifying (with the notation that $d \ln v_{t}^{p} \approx \frac{d v_{t}^{p}}{v^{p}}$ ) yields the expression in the text:

$$
\frac{d Y_{t}}{d G_{t}}=\left[\frac{-U_{C C} m c A}{-U_{N N} \frac{v^{p}}{A}-U_{C C} m c A}\right]+\left[\frac{U_{C} A}{-U_{N N} \frac{v^{p}}{A}-U_{C C} m c A}\right] \frac{d m c_{t}}{d G_{t}}+\left[\frac{U_{N N} N}{-U_{N N} \frac{v^{p}}{A}-U_{C C} m c A}\right] \frac{d \ln v_{t}^{p}}{d G_{t}}
$$

Since $U_{C C}<0$ and $U_{N N} \leq 0$, the first term in brackets must be positive and less than one. Since $U_{C}>0$, the term in brackets multiplying $\frac{d m c_{t}}{d G_{t}}$ is positive. Given that $U_{N N} \leq 0$, the term in brackets multiplying $\frac{d \ln v_{t}^{p}}{d G_{t}}$ is negative.

Next, consider the utility multiplier. Totally differentiate flow utility about a point, making use of the assumption of separability:

$$
d U_{t}=U_{C} d C_{t}+U_{N} d N_{t}+U_{G} d G_{t}
$$

Use (A.3) and (A.4) above: 


$$
d U_{t}=U_{C}\left[d Y_{t}-d G_{t}\right]+U_{N}\left[\frac{v^{p}}{A} d Y_{t}+N \frac{d v_{t}^{p}}{v^{p}}\right]+U_{G} d G_{t}
$$

Dividing by $d G_{t}$ and simplifying yields the equation in the text:

$$
\frac{d U_{t}}{d G_{t}}=\left[U_{G}-U_{C}\right]+\left[U_{C}+U_{N} \frac{v^{p}}{A}\right] \frac{d Y_{t}}{d G_{t}}+U_{N} N \frac{d \ln v_{t}^{p}}{d G_{t}}
$$

In an efficient allocation the marginal rate of substitution between labor and consumption would equal the marginal product of labor, so $-U_{N}=U_{C} \frac{A_{t}}{v_{t}^{p}}$. This means that the middle term in brackets would equal zero if the allocation were efficient. This middle term in (A.9) can be related to the "labor wedge" as defined by Chari, Kehoe, and McGrattan (2007). In particular, relative to an efficient neoclassical model we can think about the labor wedge like a distortionary tax which drives a wedge between the wage and the marginal product of labor: $-U_{N}=U_{C}\left(1-\tau_{t}\right) \frac{A_{t}}{v_{t}^{p}}$. Re-arranging terms, we can isolate $\tau_{t}$ as:

$$
\tau_{t}=\frac{1}{U_{C}}\left[U_{C}+U_{N} \frac{v_{t}^{p}}{A_{t}}\right]
$$

In other words, the middle term in brackets in (A.9) is proportional to the labor wedge as defined in Chari, Kehoe, and McGrattan (2007).

It is also possible to proceed similarly in deriving expressions for the output and utility multipliers in the medium scale model of Section 3. These are substantially more complicated than in the simpler model but reduce to the expressions from the simpler model under some parameter restrictions. Begin by defining flow utility in the social welfare function as follows:

$$
U\left(C_{t}, N_{t}, G_{t}\right)=u\left(C_{t}-b C_{t-1}\right)+v_{t}^{w} h\left(N_{t}\right)+g\left(G_{t}\right)
$$

Using the functional forms assumed in the text we would have $u\left(C_{t}-b C_{t-1}\right)=\nu_{t} \ln \left(C_{t}-b C_{t-1}\right)$, $h\left(N_{t}\right)=\psi \nu_{t} \xi_{t} \frac{N_{t}^{1+\chi}}{1+\chi}$, and $g\left(G_{t}\right)=\nu_{t} \varphi G_{t}$. It is necessary to write the expression this way to take into account the effect of wage dispersion on utility. The total derivative of flow utility about a point is:

$$
d U_{t}=u_{C} d C_{t}+v^{w} h_{N} d N_{t}+h(N) d v_{t}^{w}+g_{G} d G_{t}
$$

Totally differentiating the aggregate production function, (51), yields an expression for $d N_{t}$ :

$$
d N_{t}=\frac{v^{p}}{(1-\alpha) A \widehat{K}^{\alpha} N^{-\alpha}} d Y_{t}+N \frac{d v_{t}^{p}}{v^{p}}-\frac{\alpha}{1-\alpha} \frac{N}{\widehat{K}} d \widehat{K}_{t}
$$

Combining this with (A.12) and re-arranging yields the following expression for the utility multiplier: 


$$
\begin{aligned}
& \frac{d U_{t}}{d G_{t}}=\left[g_{G}-u_{C}\right]+\left[u_{C}+v^{w} h_{N} \frac{v^{p}}{(1-\alpha) A \widehat{K}^{\alpha} N^{-\alpha}}\right] \frac{d Y_{t}}{d G_{t}}+\left[v^{w} h_{N} N\right] \frac{d \ln v_{t}^{p}}{d G_{t}} \\
&+v^{w} h(N) \frac{d \ln v_{t}^{w}}{d G_{t}}-u_{C} \frac{d I_{t}}{d G_{t}}-v^{w} h_{N} \frac{\alpha}{1-\alpha} \frac{N}{\widehat{K}} \frac{d \widehat{K}_{t}}{d G_{t}}
\end{aligned}
$$

The first three terms in (A.14) are analogous to the "Efficiency," "Inefficiency," and "Price Dispersion" terms in the expression for the utility multiplier for the stripped down version of the model. The first term measures the difference between the marginal utilities of government spending and private consumption; the second term is the sum of the marginal utility of consumption and the marginal utility of labor divided by the marginal product of labor, all multiplied by the output multiplier; and the third term is the marginal utility of labor times labor times the reaction of log price dispersion to a change in government spending. There are three new terms which arise due to wage stickiness and the presence of investment and capital accumulation. Since $h(N)<0$, the term multiplying the reaction of log wage dispersion to a change in government spending is negative, so that if government spending increases wage dispersion the utility multiplier is lower. This effect is analogous to the impact on utility of the reaction of price dispersion. The next term is the marginal utility of consumption times the reaction of investment to government spending. The final term is a positive coefficient $\left(\right.$ since $\left.h_{N}<0\right)$ times the reaction of capital services to a change in government spending. If wages were flexible all terms related to wage dispersion would drop out. If in addition $\alpha=0$ (no capital), then the first three terms would look identical to those presented in the text. Though the welfare multiplier is again equal to the present discounted value of utility multipliers, some care must be taken when going between the two concepts, since changes in $C_{t}$ will impact future utility multipliers because of the evolution of the habit stock.

Deriving a clean expression for the output multiplier is particularly complicated by the presence of wage rigidity and the auxiliary variables related to wage-setting. To simplify things, we adopt the notation that $\mu_{t}^{w}$ is the inverse wage markup over the marginal rate of substitution. This markup is potentially time-varying because of wage stickiness. Formally:

$$
\mu_{t}^{w} w_{t}=\frac{-h_{N}}{\lambda_{t}}
$$

Here $\frac{-h_{N}}{\lambda_{t}}$ is the marginal rate of substitution between labor and consumption. This is simply a shorthand way to capture the dynamics associated with optimal wage-setting governed by equations (39)-(41) in the text. If we combine this condition with the cost-minimization condition for the optimal choice of labor by firms, we get:

$$
-h_{N}=\lambda_{t} \mu_{t}^{w} m c_{t}(1-\alpha) A_{t} \widehat{K}_{t}^{\alpha} N_{t}^{-\alpha}
$$

Totally differentiating this about a point yields: 


$$
\begin{array}{r}
-h_{N N} d N_{t}=m c \mu^{w}(1-\alpha) A\left(\frac{\widehat{K}}{N}\right)^{\alpha} d \lambda_{t}+\lambda \mu^{w}(1-\alpha) A\left(\frac{\widehat{K}}{N}\right)^{\alpha} d m c_{t}+\lambda m c(1-\alpha) A\left(\frac{\widehat{K}}{N}\right)^{\alpha} d \mu_{t}^{w} \\
+\lambda m c \mu^{w} \alpha(1-\alpha) A \widehat{K}^{\alpha-1} N^{\alpha} d \widehat{K}_{t}-\lambda m c \mu^{w} \alpha(1-\alpha) A \widehat{K}^{\alpha} N^{-\alpha-1} d N_{t} \quad(\mathrm{~A} .17)
\end{array}
$$

The Lagrange multiplier on the household's budget constraint can be written as:

$$
\lambda_{t}=u_{C}-\beta b u_{C}(+1)
$$

Here it is understood that $u_{C}(+1)$ is the derivative of the flow utility function with respect to its argument evaluated in period $t+1$. Totally differentiating this expression yields:

$$
d \lambda_{t}=\left[u_{C C}+\beta b^{2} u_{C C}(+1)\right] d C_{t}-\beta b u_{C C}(+1) d C_{t+1}
$$

The total derivative of the aggregate resource constraint is:

$$
d Y_{t}=d C_{t}+d I_{t}+d G_{t}
$$

Combining (A.20), (A.19), and (A.17) with (A.13) and re-arranging terms yields the following expression for the output multiplier:

$$
\frac{d Y_{t}}{d G_{t}}=\theta_{1}+\theta_{2} \frac{d m c_{t}}{d G_{t}}+\theta_{3} \frac{d \ln v_{t}^{p}}{d G_{t}}+\theta_{4} \frac{d \widehat{K}_{t}}{d G_{t}}+\theta_{1} \frac{d I_{t}}{d G_{t}}+\theta_{5} \frac{d \mu_{t}^{w}}{d G_{t}}+\theta_{6} \frac{d Y_{t+1}}{d G_{t}}-\theta_{6} \frac{d G_{t+1}}{d G_{t}}-\theta_{6} \frac{d I_{t+1}}{d G_{t}}
$$

Where these coeffficients are:

$$
\begin{aligned}
& \theta_{1}=\frac{-m c \mu^{w}(1-\alpha) A\left(\frac{\widehat{K}}{N}\right)^{\alpha}\left(u_{C C}+\beta b^{2} u_{C C}(+1)\right)}{\left[-h_{N N}+\lambda m c \mu^{w} \alpha(1-\alpha) A \widehat{K}^{\alpha} N^{-\alpha-1}\right] \frac{v^{p}}{(1-\alpha) A \widehat{K}^{\alpha} N^{-\alpha}}-m c \mu^{w}(1-\alpha) A\left(\frac{\widehat{K}}{N}\right)^{\alpha}\left(u_{C C}+\beta b^{2} u_{C C}(+1)\right)} \\
& \theta_{2}=\frac{\lambda \mu^{w}(1-\alpha) A\left(\frac{\widehat{K}}{N}\right)^{\alpha}}{\left[-h_{N N}+\lambda m c \mu^{w} \alpha(1-\alpha) A \widehat{K}^{\alpha} N^{-\alpha-1}\right] \frac{v^{p}}{(1-\alpha) A \widehat{K}^{\alpha} N^{-\alpha}}-m c \mu^{w}(1-\alpha) A\left(\frac{\widehat{K}}{N}\right)^{\alpha}\left(u_{C C}+\beta b^{2} u_{C C}(+1)\right)} \\
& \theta_{3}=\frac{N\left(h_{N N}-\lambda m c \mu^{w} \alpha(1-\alpha) A \widehat{K}^{\alpha} N^{-\alpha-1}\right)}{\left[-h_{N N}+\lambda m c \mu^{w} \alpha(1-\alpha) A \widehat{K}^{\alpha} N^{-\alpha-1}\right] \frac{v^{p}}{(1-\alpha) A \widehat{K}^{\alpha} N^{-\alpha}}-m c \mu^{w}(1-\alpha) A\left(\frac{\widehat{K}}{N}\right)^{\alpha}\left(u_{C C}+\beta b^{2} u_{C C}(+1)\right)}
\end{aligned}
$$




$$
\begin{aligned}
& \theta_{4}=\frac{\lambda m c \mu^{w} \alpha(1-\alpha) A \widehat{K}^{\alpha-1} N^{\alpha}+\frac{\alpha}{1-\alpha} \frac{N}{\widehat{K}}}{\left[-h_{N N}+\lambda m c \mu^{w} \alpha(1-\alpha) A \widehat{K}^{\alpha} N^{-\alpha-1}\right] \frac{v^{p}}{(1-\alpha) A \widehat{K}^{\alpha} N^{-\alpha}}-m c \mu^{w}(1-\alpha) A\left(\frac{\widehat{K}}{N}\right)^{\alpha}\left(u_{C C}+\beta b^{2} u_{C C}(+1)\right)} \\
& \theta_{5}=\frac{\lambda m c(1-\alpha) A\left(\frac{\widehat{K}}{N}\right)^{\alpha}}{\left[-h_{N N}+\lambda m c \mu^{w} \alpha(1-\alpha) A \widehat{K}^{\alpha} N^{-\alpha-1}\right] \frac{v^{p}}{(1-\alpha) A \widehat{K}^{\alpha} N^{-\alpha}}-m c \mu^{w}(1-\alpha) A\left(\frac{\widehat{K}}{N}\right)^{\alpha}\left(u_{C C}+\beta b^{2} u_{C C}(+1)\right)} \\
& \theta_{6}=\frac{-m c \mu^{w}(1-\alpha) A\left(\frac{\widehat{K}}{N}\right)^{\alpha} \beta b u_{C C}(+1)}{\left[-h_{N N}+\lambda m c \mu^{w} \alpha(1-\alpha) A \widehat{K}^{\alpha} N^{-\alpha-1}\right] \frac{v^{p}}{(1-\alpha) A \widehat{K}^{\alpha} N^{-\alpha}}-m c \mu^{w}(1-\alpha) A\left(\frac{\widehat{K}}{N}\right)^{\alpha}\left(u_{C C}+\beta b^{2} u_{C C}(+1)\right)}
\end{aligned}
$$

These expressions are algebraically complicated but nevertheless intuitive. Given assumptions on preferences, $\theta_{1}$ is positive and bound between zero and one. The parameter $\theta_{2}$ is positive and $\theta_{3}$ is negative. This means that the output multiplier is increasing in the response of real marginal cost and decreasing in the reaction of price dispersion to an increase in government spending, just as in the simpler version of the model. Coefficient $\theta_{4}$ is positive, so the multiplier is bigger the more capital services react to a change in government spending, and hence the multiplier will be bigger the less costly is variable capital utilization. The parameter $\theta_{5}$ is positive. This plays an analogous role to the response of real marginal cost to a government spending shock. If the wage markup falls when government spending increases, then $\mu_{t}^{w}$ increases, which makes the output multiplier bigger. Given that $u_{C C}<0$, the coefficient $\theta_{6}$ is positive. This means that the multiplier is bigger the more future output reacts and is smaller the more future government spending and investment react to a change in current government spending.

This expression for the output multiplier would reduce to the expression in the text under some parameter restrictions. If wages are flexible and $\epsilon_{w} \rightarrow \infty$ (so that there is no market power in wage-setting), then $\mu_{t}^{w}=1$ at all times, so that $\frac{d \mu_{t}^{w}}{d G_{t}}=0$. If $b=0$ (no habit formation), then $\theta_{6}=0$ and the coefficients on reactions of future endogenous variables to changes in current government spending drop out. If $\alpha=0$ (so that capital is not productive), then $\theta_{4}=0$ and there would be no investment, so that $\frac{d I_{t}}{d G_{t}}=0$. This would then leave just the first three terms. With competitive wage-setting, no habit formation, and no capital, the expressions for $\theta_{1}, \theta_{2}$, and $\theta_{3}$ would reduce to exactly the same expressions presented in the text. 